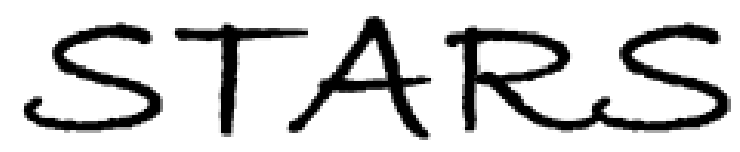

University of Central Florida

STARS

$1-1-2000$

\title{
Understanding the customer base of service providers: An examination of the differences between switchers and stayers
}

Jaishankar Ganesh

University of Central Florida

Mark J. Arnold

University of Central Florida

Kristy E. Reynolds

University of Central Florida

Find similar works at: https://stars.library.ucf.edu/facultybib2000

University of Central Florida Libraries http://library.ucf.edu

This Article is brought to you for free and open access by the Faculty Bibliography at STARS. It has been accepted for inclusion in Faculty Bibliography 2000s by an authorized administrator of STARS. For more information, please contactSTARS@ucf.edu.

\section{Recommended Citation}

Ganesh, Jaishankar; Arnold, Mark J.; and Reynolds, Kristy E., "Understanding the customer base of service providers: An examination of the differences between switchers and stayers" (2000). Faculty Bibliography 2000s. 7859.

https://stars.library.ucf.edu/facultybib2000/7859

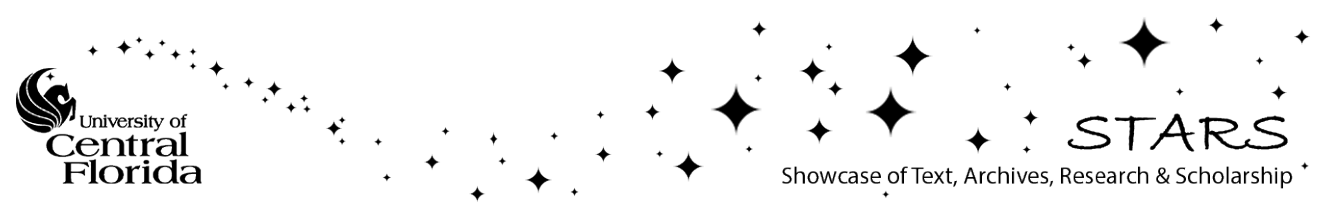




\section{Understanding the Customer Base of Service Providers: An Examination of the Differences Between Switchers and Stayers}

Creating and maintaining customer loyalty has become a strategic mandate in today's service markets. Recent research suggests that customers differ in their value to a firm, and therefore customer retention and loyalty-building efforts should not necessarily be targeted to all customers of a firm. Given these sentiments, it is becoming increasingly necessary for firms to have a thorough understanding of their customer base. Yet current knowledge is limited in providing insights to firms regarding the differences within their customer base. This research comprises two studies in which the authors examine the differences among internal customer groups in a service industry. As theory suggests and as is empirically validated here, customers who have switched service providers because of dissatisfaction seem to differ significantly from other customer groups in their satisfaction and loyalty behaviors. The findings offer some interesting implications for both marketing theory and practice.

0 ver the past decade, researchers have recognized that customer switching behavior can have deleterious effects on the profitability and viability of firms in today's marketplace. For example, statistics reveal that U.S. corporations lose half their customers in five years and that customer disloyalty at these rates stunts corporate performance by $25 \%$ to $50 \%$ (Reichheld and Teal 1996). However, researchers have also observed that with each additional year of a relationship between a company and a consumer, the customer becomes less costly to serve because of learning effects and decreased servicing costs. Over time, loyal customers build businesses by buying more, paying premium prices, and providing new referrals through positive word of mouth (Keaveney 1995; O' Brien and Jones 1995; Reichheld and Kenny 1990). Given this evidence, it is no wonder that companies are rushing to implement retention and loyalty programs.

However, for all the anticipated benefits of customer retention and loyalty, problems have become evident in some of these efforts (Dowling and Uncles 1997). Central to these concerns is researchers' and practitioners' realization that (1) not all customers should be targeted with retention and loyalty efforts and (2) some of the most satisfied and loyal customers might still switch for reasons beyond the control of the firm and at times even beyond the control of

Jaishankar Ganesh, Mark J. Arnold, and Kristy E. Reynolds are assistant professors, Department of Marketing, University of Central Florida. The authors thank the anonymous JM reviewers for their insightful comments and constructive feedback that helped shape this article. The authors gratefully acknowledge the financial support of the Department of Marketing and the Office of Sponsored Research at the University of Central Florida. The authors thank Alicia Leuven for her assistance in data collection and Ronald Michaels, Raj Echambadi, Ronald Hess, and Chris White for their insightful comments and suggestions. the customer. Although it is encouraging to note the increasing awareness that not all customers are alike (Blattberg and Deighton 1996; Reichheld 1993), little is known about how and why they differ. Simply put, if important attitudinal and behavioral differences can be identified among various customer groups, service providers can efficiently identify and target customers as part of a broader acquisition, value assessment, and retention strategy. This, in essence, is the focus of the current study.

A basic assumption of this research is that, at its most fundamental level, a firm's customer base can be thought to comprise two groups of customers: (1) customers who have switched from other service providers (whom we refer to as "switchers") and (2) those who have not (the first-time adopters whom we refer to as "stayers"). The switchers can be further classified into two types: dissatisfied switchers and satisfied switchers (customers who switch for reasons other than dissatisfaction, e.g., jobrelated relocation). An understanding of how these customer groups differ in their attitude and behavior toward the firm might provide crucial insights for designing and implementing effective customer acquisition and retention strategies.

Prior research has related switching behavior/intentions to perceptions of quality (Rust and Zahorik 1993), dissatisfaction (Crosby and Stephens 1987), and service encounter failures (Kelley, Hoffman, and Davis 1993). However, the predominant focus of the research addressing customer switching behavior has been the costs to a firm because of customer switching and the costs of replacing customers who have defected (Keaveney 1995). In other words, prior research has focused on the "switched-from" firm and not the "switched-to" firm. There is a dearth of research examining what happens to customers after they have switched in regard to satisfaction with and loyalty to the new firm. 
We address this issue by proposing that customers who switch to a firm because of dissatisfaction with a previous service provider constitute a key customer group that is characterized by a propensity for higher levels of satisfaction with and loyalty toward the new firm and accordingly could be central to a firm's acquisition and retention efforts. Drawing from rich theories on customer satisfaction and loyalty, we attempt to identify attitudinal and behavioral factors that differentiate the three groups of customers (dissatisfied switchers, satisfied switchers, and stayers) in the retail banking industry. In effect, the major objectives of this study are

1. to examine whether the three groups of customers differ in their overall satisfaction with the service provided by the current firm (in the case of switchers, this would be the switched-to firm),

2. to investigate the role of satisfaction with the various aspects of the service in differentiating among the groups, and

3. to examine whether the groups differ in their involvement with and loyalty behavior toward the service.

This research comprises two studies. In Study 1, on the basis of a thorough review of relevant literature, we develop and test research hypotheses pertaining to the objectives of the study. Then we describe the data, the analyses used in testing the hypotheses, and the research results. Study 2 replicates the findings of Study 1 in a larger sample and explores some interesting issues that arise from the results of the first study. The issues we examine in Study 2 include (1) the influence of time (tenure as a customer with the current firm) on the hypothesized difference among the groups in terms of their overall satisfaction with the service provider, (2) differences within the switcher groups in terms of their prior switching experiences, and (3) differences within the three groups in terms of other relevant variables, such as commitment, dependence, and risk aversion. In Study 2, we discuss the relevant literature pertaining to these three issues and empirically examine these relationships. Finally, on the basis of the findings of both studies, we draw managerial implications, discuss limitations pertaining to the generalizability of the results, and offer guidelines for further research.

\section{Theoretical Foundation and Research Hypotheses}

The literature on service satisfaction and switching behavior suggests that three critical constructs should be examined when the differences among customers are investigated: customer loyalty, customer satisfaction, and involvement. First, the core of a valuable customer base consists of loyal customers. Research has shown that loyal customers are more profitable not only in the short run because they spend more (O'Brien and Jones 1995) but also in the long run because they spread positive word of mouth (Reichheld and Teal 1996). Loyal customers most directly affect profit by ensuring a steady stream of future customers (Oliver 1997). Because of their current and potential future value, loyal customers are logically at the heart of a company's most valuable customer group.
Second, satisfaction is also acknowledged as a key determinant of not only continued patronage but also firm profitability. Prior research has shown that satisfied customers exhibit reduced price elasticities and greater competitive resistance and that firms enjoy reduced failure costs and an enhanced reputation (Anderson, Fornell, and Lehman 1994; Fornell 1992). The perspective of the satisfaction and services research suggests that satisfaction is also a significant antecedent to postpurchase attitude and repeat purchase intentions, as well as several other beneficial behavioral intentions (Anderson 1994; Zeithaml, Berry, and Parasuraman 1996).

Third, involvement has been shown to play a key role in this area of research. Researchers have shown the important moderating influence of both purchase involvement (Oliva, Oliver, and MacMillan 1992) and ego involvement (Bloemer and Kasper 1995) on the satisfaction-loyalty relationship and the antecedent role that these variables play in determining brand commitment (Beatty, Kahle, and Homer 1988).

However, to our knowledge, no research has yet examined whether or how these critical variables are likely to differ among the three customer groups-dissatisfied switchers, satisfied switchers, and stayers. Drawing on the rich theoretical foundation in this area, in the current study we attempt to formulate and test specific hypotheses regarding differences among the three customer groups in terms of customer satisfaction, involvement, and loyalty.

\section{Overall Customer Satisfaction}

Two broad theoretical bases are directly relevant to our study: the expectancy-disconfirmation paradigm (Oliver 1980) and comparison-level theory (Thibaut and Kelly 1959).

Expectancy-disconfirmation theory. According to the expectancy-disconfirmation paradigm (Oliver 1980), consumers judge satisfaction with a product by comparing previously held expectations with perceived product performance. If performance is above (below) expectations, positive (negative) disconfirmation occurs and increases (decreases) in satisfaction are expected. Thus, consumer satisfaction is a function of expectations and disconfirmation, and predictive expectations are used as the standard of comparison.

More important, Oliver (1997) suggests that two underlying forces drive the expectancy-disconfirmation process: assimilation and contrast effects. Assimilation strategy implies a heavy reliance on expectations in arriving at satisfaction judgments, such that consumers are thought to assimilate performance toward previously held expectations (Oliver 1997). Similar to adaptation-level theory (Helson 1964), expectations are viewed as the anchor for future performance evaluations and are believed to take on increased importance under conditions of high performance ambiguity.

Alternatively, contrast effects manifest themselves in satisfaction judgments, as consumers are likely to exaggerate the perceived levels of performance so that performance levels that exceed expectations tend to be rated much higher than they really are (Oliver 1997). In effect, a consumer is believed to magnify perceptions of performance in the direction of the performance discrepancy. Oliver (1997) notes that disconfirmation, a proxy for contrast effects, is 
strongest under conditions of high salience, or involvement, and when consumers are easily able to discern performance differences.

In this context, the dissatisfied switchers are likely to experience higher levels of involvement (discussed subsequently) and thus should easily discern changes in the performance levels from the previous dissatisfying service experience to the new one. Thus, higher involvement suggests that the satisfaction judgments of the dissatisfied switchers will be disconfirmation driven. However, involvement tends to have the effect of magnifying disconfirmation effects, regardless of whether an expectation is positively or negatively confirmed. As such, elevated levels of involvement can, in some cases, have a deleterious effect on the dissatisfied switcher's level of satisfaction as well (Oliver 1997). Thus, the question becomes whether the dissatisfied switchers are likely to experience positive disconfirmation or negative disconfirmation, a question addressed by comparison-level theory.

Comparison-level theory. According to Thibaut and Kelley (1959), the key to determining the level of satisfaction with and motivation to remain in a relationship is the concept of comparison levels, of which two standards are employed: the comparison level and the comparison level for alternatives. The comparison level is "the standard against which a member evaluates the 'attractiveness' of the relationship or how satisfactory it is" (Thibaut and Kelley 1959, p. 21). Thibaut and Kelley (1959) advance the general hypothesis, which is central to our research focus, that the comparison level tends to move to the level of outcomes currently being attained. Thus, a customer who has experienced declining outcomes with a previous service provider and switches because of dissatisfaction will enter a new relationship with a reduced comparison level. Therefore, we expect this customer to exhibit high levels of satisfaction relative to other customers who have experienced relatively little change in their comparison levels.

Prior consumer research (e.g., LaTour and Peat 1979, 1980), as well as interorganizational exchange research (e.g., Anderson and Narus 1990), has generally found support for comparison-level theory predictions regarding prior experience and satisfaction. However, although theory is instructive regarding the generalized operation of expectations and comparison standards, it remains relatively silent on the specific time frame in which these operations are supposed to occur. Therefore, the predictions that are suggested by comparison-level theory should be treated with a degree of caution.

In summary, expectancy-disconfirmation theory predicts that satisfaction judgments of the dissatisfied switchers will be disconfirmation driven, largely because of the salience of the service to the customer, and that satisfaction judgments will be more extreme for this group. Consideration of this theoretical prediction in the light of comparisonlevel predictions of higher satisfaction, or positive disconfirmation, suggests that the dissatisfied switchers will be more satisfied than the other customer groups with their new service provider. Therefore,
$\mathrm{H}_{1}$ : All else being equal, compared with satisfied switchers and stayers, dissatisfied switchers are more satisfied with their current service providers.

A fundamental difference between customers who have switched for reasons other than dissatisfaction and customers who have not switched at all is the notion that the satisfied switchers have prior experience with other service providers in the same category (i.e., experience-based norms). This suggests that differences exist in the sets of expectations used by these two groups and accordingly implies differences in the levels of subsequent satisfaction judgments. Although dissatisfied switchers also possess prior experience, the nature and valence of their experience differ from that of satisfied switchers, and this difference suggests opposite effects in subsequent satisfaction judgments.

Researchers have shown that the nature and amount of a consumer's experience with an evoked set of brands are important determinants of the satisfaction process (Cadotte, Woodruff, and Jenkins 1987; Woodruff, Cadotte, and Jenkins 1983). Focal brand expectations are likely to result from the decision to use the brand, but consumers also enter this scenario with different levels of prior product experience. Specifically, consumers with broader experience are likely to develop different standards of comparison than consumers with less experience, such that prior experience influences both focal brand expectations and product-category performance norms. These latter standards are closely aligned with norms that reflect what the focal brand should be able to achieve, not just predictions as to what the focal brand will achieve. Although research in this area specifies the overall nature of these expectation processes, little guidance is offered regarding the specific time frame for these operations.

Oliver (1997) suggests that these experience-based norms, when employed as expectations, determine the relative level of a consumer's expectations in a better than/worse than sense. As such, it is reasonable to suggest that expectations held by satisfied switchers will be at least at the levels previously held. This line of argument finds support in studies that suggest that a positive relationship exists between prior experience and current levels of expectations (Zeithaml, Berry, and Parasuraman 1993), as well as the upward shift of should expectations over time (Boulding et al. 1993). The preceding discussion suggests the following:

$\mathrm{H}_{2}$ : Compared with stayers, satisfied switchers are less satisfied with their current service providers.

\section{Customer Satisfaction with Service Dimensions}

Although investigations of overall satisfaction provide useful insights into the various customer groups, further exploration of satisfaction with service dimensions provides a more detailed look into the factors that drive customer satisfaction. Researchers have suggested that satisfaction with specific service attributes should be measured routinely when customer satisfaction and switching behavior are investigated (Rust and Zahorik 1993). The reasoning behind such advice relies on the multidimensional nature of perceptions of service quality and satisfaction, such that some 
dimensions may be perceived as more important than others in determining overall satisfaction and intentions to repatronize or switch. Furthermore, by investigating individual service dimensions, researchers are better able to provide actionable managerial guidance regarding which service areas a firm should concentrate on in efforts to build loyalty among current customers and attract profitable prospects.

Service quality research has shown that five dimensions of service are most relevant in determining perceptions of service quality and satisfaction: tangibility, reliability, responsiveness, assurance, and empathy (Parasuraman, Zeithaml, and Berry 1985, 1988, 1994). Other research has shown that service factors such as convenience and warmth are dimensions of service satisfaction and loyalty (Rust and Zahorik 1993). An underlying element of these various service dimensions is the notion of interaction with firm representatives, or a broader "people factor," which theory suggests may be the most important determinant of overall satisfaction and repeat patronage intentions in many service industries.

According to the services marketing literature, service encounters are first and foremost social encounters (Berry 1983; Czepiel 1990). The purchase of a service is a process that relies on the interaction between the service provider and the customer, and therefore service encounters are considered interpersonally relational in nature (see Crosby, Evans, and Cowles 1990; Crosby and Stephens 1987; Iacobucci and Ostrom 1996; Ostrom and Iacobucci 1995). As a result, customer perceptions of contact employees will affect their perceptions of the company and greatly influence customer satisfaction (Bitner, Booms, and Mohr 1994; Goff et al. 1997; Iacobucci and Ostrom 1996; Rust and Zahorik 1993; Westbrook 1981).

This factor may be best understood as a problem-solving issue. Service failure and recovery research suggests that interpersonal contact during service recovery is a factor in determining ultimate satisfaction and perceptions of service quality (Kelley, Hoffman, and Davis 1993). In other words, service personnel appear to be key to service recovery and other related encounters, and because of this the customer's ultimate satisfaction or dissatisfaction is likely to be couched in terms of how the employees handled the service problem. Therefore, it makes sense that the people factor would discriminate better than other factors among customer groups with presumably differing service experiences. However, note that the importance of the people factor is likely to vary across industries.

In summary, this research implies that satisfaction with service dimensions related to interaction with a firm's representatives is likely to be more important than satisfaction with the other service dimensions and, in the research context here, is likely to be a discriminator among the various customer groups of interest. As such, we hypothesize the following:

$\mathrm{H}_{3}$ : Satisfaction with the people factor of the service is a stronger discriminant of the three groups of customers than satisfaction with the other aspects of the service.

\section{Involvement}

The two forms of involvement relevant to this research are purchase and ego involvement. Purchase involvement relates to the level of concern for or interest in the purchase process that is triggered by the need to consider a particular purchase. Purchase involvement can best be understood as the cost, effort, or investment in a purchase (Mittal and Lee 1989; Zaichkowsky 1985). It is the outcome of a person's interaction with a product and the purchase situation (Beatty, Kahle, and Homer 1988) and is similar to, but more narrowly focused than, Houston and Rothschild's (1978) definition of situational involvement. Because customers are likely to experience changes in levels of purchase involvement when key facets of the relevant environment change (Beatty, Kahle, and Homer 1988), such as a service switch, stayers are not likely to experience purchase involvement in a manner similar to that of switchers. Therefore, we hypothesize differences only between the two switching groups.

Switchers who are dissatisfied should be expected to have experienced critical changes in levels of perceived service quality, whether they relate to core service failures, service encounters, or service design (Keaveney 1995). Negative outcomes from such experiences are highly salient and are likely to be distinctive, atypical, and emotionally charged, and such information is bound to be encoded more thoroughly and be more easily retrieved from memory (Folkes 1988). Such prior experiences will be factored into expectations and apprehensions about future service experiences (Oliver and Winer 1987), thereby affecting perceived risk associated with service selection and use (Mittal and Lee 1989). Because the result of such cognitive evaluations is an increase in purchase involvement (Bloch 1982; Bloch and Richins 1983; Houston and Rothschild 1978), we expect that the dissatisfied switchers experience greater levels of purchase involvement than customers who switch for other reasons. This suggests the following:

$\mathrm{H}_{4}$ : Compared with satisfied switchers, dissatisfied switchers exhibit higher levels of purchase involvement.

Ego involvement has been defined as the "importance of the product to the individual and to the individual's self concept, values, and ego" (Beatty, Kahle, and Homer 1988, p. 150). Ego involvement is similar to enduring involvement, which is defined as an ongoing concern for a particular product class and relatively independent of purchase situations (Bloch and Richins 1983; Richins and Bloch 1986). Although ego involvement has also been conceptualized as a relatively stable phenomenon (Richins and Bloch 1986), researchers have recognized several psychological mechanisms that are likely to influence the levels of ego involvement people experience.

One such mechanism is familiarity, which according to Sherif and Cantril (1947), can increase ego involvement. Customers who have experience with only one service provider - the stayers - are more likely to experience higher degrees of familiarity and to develop a favorable attitude toward a particular service provider and the service category in general. Thus, their level of ego involvement is likely to be higher than that of the other customer groups. Therefore, we hypothesize the following:

$\mathrm{H}_{5}$ : Compared with stayers, both dissatisfied and satisfied switchers exhibit lower levels of ego involvement. 
Customers who switch because of dissatisfaction are likely to experience changes in their levels of ego involvement with a specific service category. A previously positive element of self-definition that has now become negative (i.e., the service) is not likely to continue to play the same role in defining the customer's self-identity. The manifestation of this cognitive process is a reduction in the level of ego involvement by the customer regarding the service relationship. Such changes in ego involvement are not unexpected, as ego involvement has long been conceptualized as changing in response to the stresses and strains that people experience (Sherif and Cantril 1947).

Furthermore, dissatisfying service experiences, particularly those that result from service failures, accumulate up to the point of service switching and are salient and memorable. This negative consumption experience should influence the extent of enduring importance that a person places on the product or service category (Bloch and Richins 1983). This is particularly relevant because consumer researchers have identified several psychological coping mechanisms that relate to devaluing, or decreasing the importance of, the object causing psychological stress (Pearlin and Schooler 1978). A dissatisfying relationship that results in termination would influence the degree of importance consumers place on that service in defining their self-concept and as a result would influence the level of ego involvement associated with that service category. This leads us to hypothesize the following:

$\mathrm{H}_{6}$ : Compared with satisfied switchers, dissatisfied switchers exhibit lower levels of ego involvement.

\section{Customer Loyalty}

An important consideration in a service firm's customer base is the degree to which its customers are loyal. We conceptualize customer loyalty as a combination of both commitment to the relationship and other overt loyalty behaviors. This is consistent with prior loyalty research (see Day 1969; Dick and Basu 1994). Again, we rely on the work of Thibaut and Kelley (1959) and the loyalty literature in formulating our hypotheses related to group differences.

Comparison-level theory revisited. The comparison level for alternatives is the standard a person uses in deciding whether to remain in a relationship and can be defined informally as the "lowest level of outcomes a person will accept in light of available alternative opportunities" (Thibaut and Kelley 1959, p. 21). The position of the comparison level for alternatives on a person's hypothetical outcome continuum is based largely on the range of outcomes believed to exist in the next best alternative relationship, and as soon as current perceived outcomes drop below comparison level for alternatives, the person is motivated to leave the relationship.

Several points become relevant regarding customer loyalty. First, Thibaut and Kelley (1959) suggest that the greater the distance between the comparison level for alternatives and actual outcomes, the closer the person comes to maximizing the rewards-cost trade-off in the relationshiptherefore, the greater is the dependence and commitment on the part of the customer to continue the relationship. Recent research has shown the fundamental role that commitment plays in the construct of customer loyalty (Assael 1987; Morgan and Hunt 1994), as well as the close relationship dependence and commitment have in relational exchanges (Bendapundi and Berry 1997; Ganesan 1994).

Second, the outcome continuum allows for the relative positions of comparison level, comparison level for alternatives, and actual outcomes to differ (Thibaut and Kelley 1959), such that certain orderings are suggestive of strong, or true, customer loyalty, whereas other orderings suggest conditions similar to spurious loyalty (e.g., Day 1969; Dick and Basu 1994). For example, when a customer's comparison level exceeds actual outcomes as well as the comparison level for alternatives, the customer is relatively dissatisfied yet is also relatively dependent on the relationship-a situation that is analogous to spurious loyalty. Thus, the application of comparison-level theory to customer loyalty processes exhibits a certain degree of theoretical discrimination in regard to the different types of customer loyalty.

Finally, a closer inspection of switching behavior in light of the dynamics of comparison levels provides further insight into the loyalty phenomenon. As perceived outcomes fall below a person's comparison level for alternatives, that person is motivated to leave the relationship, the consideration set for available alternatives is reduced, and the comparison level for alternatives falls to represent the next best set of outcomes that could be attained (Thibaut and Kelley 1959). As such, compared with other customer groups, dissatisfied switchers are likely to move from a state in which both outcomes and the comparison level are below the comparison level for alternatives to a state in which perceived outcomes are significantly above both the comparison level and the comparison level for alternatives - a situation that is conducive to higher levels of both satisfaction and loyalty. Prior research has provided a limited test of this proposition, showing that consumers with poor prior experience exhibit higher satisfaction and repeat purchase intentions with the new brand (LaTour and Peat 1980; Mazursky, LaBarbera, and Aiello 1987).

Customers who switch for other reasons or customers who do not switch at all will experience relatively small shifts in their comparison level and comparison level for alternatives largely because perceived actual outcomes with their current service provider change little and their consideration set for available alternatives remains relatively unchanged. The likely result of such mechanics is suggestive of considerable differences in both satisfaction and loyalty between customers who have switched service providers because of dissatisfaction and other customer groups. This leads us to hypothesize the following:

$\mathrm{H}_{7}$ : Compared with satisfied switchers and stayers, dissatisfied
switchers are more loyal to their current service.

Intuitively, it appears that customers who have switched service providers for reasons other than dissatisfaction are less likely to hold negative attitudes and feelings toward their previous service provider. Many of these customers are likely to remember their previous service provider in a positive light and factor their previous experience into current expectations, emotions, and behavior. Although these various psychological constructs have been conceptualized to be antecedents to customer loyalty (Dick and Basu 1994), one 
particularly important variable appears to be the conative antecedent of perceived switching costs. Higher perceived switching costs are believed to result in higher loyalty attitudes and intentions. Because satisfied switchers have prior experience with other service providers as well as the process of switching service providers, it can reasonably be assumed that the inhibiting influence of perceived switching costs will be less prevalent within this group and subsequently will have a negative influence on the formation of loyalty.

We also see evidence in the brand-switching literature, which has shown that consumers who switch because of extrinsic factors (e.g., coupons, price) are more likely to exhibit lower satisfaction and repeat purchase intentions with the switched-to brand than consumers who are intrinsically motivated (e.g., dissatisfaction, the desire to try a new brand) (LaBarbera and Mazursky 1983; Mazursky, LaBarbera, and Aiello 1987). Given this evidence, we have a basis for suggesting that the satisfied switchers are likely to exhibit lower levels of loyalty than their nonswitching counterparts. Therefore, we hypothesize the following:

$\mathrm{H}_{8}$ : Compared with stayers, satisfied switchers are less loyal to their current service providers.

\section{Research Method}

\section{Instrument Design and Data Collection}

To test the hypotheses, we designed an instrument to collect information on (1) consumers' use of banking services (e.g., presence of accounts in more than one bank; type of accounts held; whether the customer had switched banks; if so, why), (2) overall satisfaction with the current primary bank, (3) satisfaction with the individual aspects of the banking service, (4) purchase and ego involvement associated with the choice and usage of the bank, (5) consumers' sense of loyalty toward the bank, and (6) demographic characteristics. Trained interviewers obtained the data for the study over the telephone. We pretested the instrument on a small sample $(n=10)$, and on the basis of the results of the pretest, we reduced the length of the instrument and refined the script.

Trained interviewers, using the final script, conducted the interviews, which lasted an average of 12 minutes. The sample was randomly drawn from the residential section of the current local telephone directory of a major metropolitan area in the southeast region of the United States. Sampling units were selected from the directory proportionate to the alphabetical listings. Because this approach toward sampling excludes households with unlisted numbers, it (unlike a random-digit dialing approach) has the potential to introduce biases. However, the bias can be considered minimal, given the relatively low proportion of unlisted numbers in the general population.

Respondents were first asked two screening questions to check whether they currently have an account (any type) with a bank and qualify them as the household decision maker regarding banking services. Also, because some customers were likely to have accounts in multiple banks, the respondents (in such cases) were specifically requested to answer all the questions with respect to their primary bank, that is, the bank they consider their major banking service supplier.

Calls were made during weekday evening hours to maximize the probability of reaching the decision maker. Interviewers made 828 calls, which resulted in 217 completed interviews. A total of 333 calls resulted in no answer, a busy signal, or no contact after two callback attempts. Refusals totaled 278, which resulted in an effective response rate of $43.8 \%$ (217/495). Seventeen of the completed interviews were later considered unusable because of missing values, which resulted in 200 usable responses.

\section{Measures of Constructs}

To classify customers into the three hypothesized groups on the basis of their switching behavior, respondents were asked a two-part question: (1) whether their current bank was their first bank or they had switched from a previous bank and (2) if they had switched, the reason they switched from their previous bank to their current bank. The options for switching included (1) overall dissatisfaction with the service of the previous bank or (2) reasons other than dissatisfaction (e.g., job relocation, moving out of the previous bank's service area, the previous bank closed down or was bought out by a different bank). Respondents were then placed into one of three categories: (1) those for whom their current bank was their first bank (i.e., those who had never switched-the stayers), (2) those who switched because they were dissatisfied overall with the service they received from their previous bank (i.e., the dissatisfied switchers), and (3) those who switched for reasons other than dissatisfaction (i.e., the satisfied switchers).

We hypothesize that these three groups differ in their satisfaction with the service of their current bank, their level of purchase and ego involvement with the banking service, and their loyalty behaviors toward the current bank. Several measures of these three constructs have been proposed and empirically validated in the literature. The items used to measure these constructs in this research were obtained from prior studies that were most relevant to the current research setting.

For example, measures of consumer satisfaction found in the literature include those proposed by Anderson and Sullivan (1993), Bearden and Teel (1983), Churchill and Suprenant (1982), Fornell (1992), Fornell and colleagues (1996), Oliva, Oliver, and MacMillan (1992), Oliver (1980, 1992, 1993), Oliver and Swan (1989), Rust and Zahorik (1993), Tse and Wilton (1988) and Westbrook and Oliver (1981). On the basis of prior research measures, we measure satisfaction in two ways. First, we obtained a global measure of satisfaction by means of a single item: "Overall, how satisfied are you with your bank?" Second, to measure consumers' satisfaction with the various aspects of the banking service, we employed a scale comprising 11 items. Given the boundaries of this research study, the scale was composed mostly of items developed by Rust and Zahorik (1993). On the basis of an examination of the literature and of focus groups conducted in a previous study, Rust and Zahorik (1993) identify nine key attributes that define customers' ongoing relationships with their primary bank. Two items were added to this nine-item scale, and all items were measured on a five-point Likert scale that ranged from "very dissatisfied" to "very satisfied." 
The literature also provides several definitions and measures of involvement (Cohen 1983). Because of the current research context, we restricted the measures of involvement to those that apply specifically to purchase and ego involvement. We used a total of nine items adapted from prior studies (Beatty and Smith 1987; Bloch 1982; Bloemer and Kasper 1995; Laurent and Kapferer 1985; Mittal 1989; Mittal and Lee 1989; Richins and Bloch 1986; Salma and Tashchian 1985; Zaichkowsky 1985) to measure the involvement constructs.

Finally, early studies on brand loyalty measure loyalty on the basis of repeat patronage or repeat purchase intentions. But researchers generally agree that operationalizing loyalty simply as repeat patronage is too simplistic and does not capture the multidimensionality of the construct (Bloemer and Kasper 1995; Day 1969; Dick and Basu 1994; Jacoby and Chestnut 1978; Jacoby and Kyner 1973). In line with this argument, recent studies have defined and measured loyalty using multiple items including repeat patronage, self-stated retention, price insensitivity, resistance to counterpersuasion, and the likelihood of spreading positive word of mouth (e.g., Dick and Basu 1994; Fornell 1992; Fornell et al. 1996; Jacoby and Kyner 1973). Adapting these measures, we use six related items to operationalize the customer loyalty construct. We measured the items for both involvement and loyalty constructs on a five-point Likert scale that ranged from "strongly disagree" to "strongly agree."

\section{Data Analysis and Results}

A preliminary analysis of the data revealed that the respondents were almost evenly split by sex (51.5\% male and $48.5 \%$ female). Approximately $47 \%$ of the respondents were 35 years of age or younger, and the average household income of approximately $36 \%$ of the sample was greater than $\$ 50,000$. Almost $57 \%$ of the sample had earned at least an undergraduate degree, and approximately $62 \%$ of the sample was married. Of the 200 respondents, $27 \%$ were stayers, $15.5 \%$ were dissatisfied switchers, and the remaining $57.5 \%$ were satisfied switchers. The percentage of dissatisfied switchers seems to be in line with the findings of Rust and Zahorik (1993), who report that approximately $21 \%$ of switchers were dissatisfied with their previous bank. Overall, the data revealed good variance in the responses for all other items measured. In Table 1, we provide a correlation matrix of the research constructs.

\section{Overall Satisfaction}

$\mathrm{H}_{1}$ and $\mathrm{H}_{2}$ pertain to differences among the three groups in regard to their overall satisfaction with their current primary bank. $\mathrm{H}_{1}$ states that compared with satisfied switchers and stayers, dissatisfied switchers are more satisfied with their current service providers, and $\mathrm{H}_{2}$ states that satisfied switchers are less satisfied with their current service providers than stayers. To test these hypotheses, we compared group means on the overall satisfaction item using analysis of variance (ANOVA). The results (see Table 2) reveal that the groups differ significantly in their overall satisfaction with their current bank. Furthermore, the results show that the dissatisfied switchers (mean score $=4.61$ ) are significantly more satisfied with their current bank than the other two groups and that the satisfied switchers (mean score $=4.04$ ) are significantly less satisfied than the stayers (mean score $=4.28$ ). This provides support for hypotheses $\mathrm{H}_{1}$ and $\mathrm{H}_{2}$.

To test the subsequent hypotheses related to group differences with regard to satisfaction with the individual aspects of the service, involvement, and loyalty, the individual measures of these constructs were factor analyzed to determine their measurement properties and dimensionality. For the satisfaction items, a scree plot of the eigenvalues indicated a four-factor solution. In Table 3, we present the items and the corresponding factor loadings. Four items loaded highly on the first factor. Because these items referred to problem-solving and human dimensions of the bank, they were interpreted as the "people factor." Three items loaded on the second factor, which was labeled "locational convenience," and the third factor was characterized as "ease of transaction" and included three items. One item, which refers to satisfaction with the cost of checking account, loaded on its own and was termed the "cost factor." Furthermore, the test of intercorrelation among the items loading on the individual factors suggests a high degree of reliability: Cronbach's coefficient alphas values were $.92, .86$, and .75 , respectively, for the first three factors.

A factor analysis of the involvement items revealed a twofactor solution. The six items loading on the first factor corresponded to being involved with the particular purchase decision of choosing a bank. Therefore, this factor was interpreted as "purchase involvement." The second factor, which contained three items, pertains to the "ego involvement" dimension. In Table 4, we present the involvement items and the corresponding factor loadings. The coefficient alphas for the items loading on the factors are .84 and .71, respectively, which indicates an acceptable level of reliability (Nunnally 1978).

A factor analysis of the six items that measured customers' loyalty toward their current banks revealed a clean two-factor solution. We present the items and the corresponding factor loadings in Table 5. On the basis of prior research findings, we expected all six items to load highly on a single factor. This result (a two-factor solution), though surprising, makes intuitive sense. The three items that load on the first factor correspond to customers' willingness to spread positive word of mouth and their intentions to use more of the bank's services. The remaining three items loading on the second factor correspond to competitive price immunity and self-stated retention. Therefore, we label our first factor "active loyalty" and the second factor "passive loyalty." The coefficient alphas for the items loading on the factors are .77 and .72, respectively, which indicates an acceptable level of reliability (Nunnally 1978).

For a test of the remainder of our hypotheses, we performed a multiple discriminant analysis. We used discriminant analysis, because this method determines the ability of the criterion variables to discriminate among the three groups of customers. To check the validity of the models, we employed a proportional 50/50 split-sample validation approach, and we present the results for both the analysis and the holdout sample for each of the three cases.

To test $\mathrm{H}_{3}-\mathrm{H}_{8}$, we performed individual discriminant analyses using the four satisfaction, the two involvement, and the two loyalty dimensions. Subsequently, we performed an overall discriminant analyses that included all eight factors as criterion variables. Because the results of the 


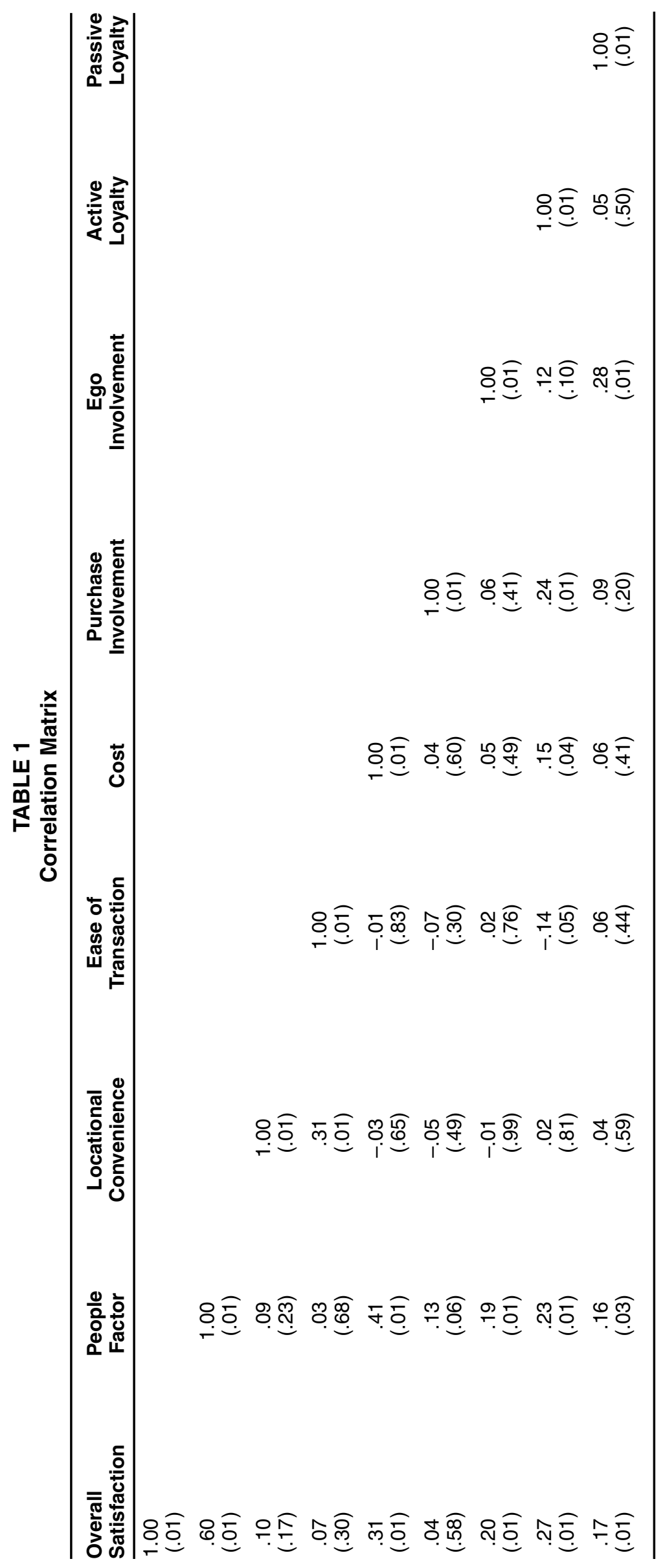


individual discriminant analyses were in complete agreement with the overall analyses, we restrict our discussion to the findings of the overall analyses. In Table 6, we provide the results of the three-group discriminant analysis performed with all eight factors included as criterion variables. Both discriminant functions are significant, and the results reveal that six of the eight factors are significant in discriminating among the groups. The potency indices suggest that on the basis of relative discriminatory power, the variables can be ordered as follows: the people factor, cost, ego involvement, purchase involvement, active loyalty, and passive loyalty. A stepwise discriminant analysis resulted in the

TABLE 2

Overall Satisfaction Measure: Difference Between Group Means

\begin{tabular}{lccc}
\hline Measure & Groups & Mean Scores & $\begin{array}{c}\text { Difference Between } \\
\text { Means }\end{array}$ \\
\hline $\begin{array}{l}\text { Overall, how satisfied are } \\
\text { you with your bank? }\end{array}$ & $\begin{array}{c}\text { Stayers } \\
(\mathrm{n}=54)\end{array}$ & 4.28 & $\begin{array}{c}\text { Stayers versus } \\
\text { satisfied switchers }\end{array}$ \\
& $\begin{array}{c}\text { Satisfied switchers } \\
(\mathrm{n}=115)\end{array}$ & $(.0001)$ & $\begin{array}{c}\text { Stayers versus } \\
\text { dissatisfied switchers -.33 }\end{array}$ \\
& Dissatisfied switchers \\
& $(\mathrm{n}=31)$ & 4.04 & $\begin{array}{c}\text { Satisfied switchers } \\
\text { versus dissatisfied } \\
\text { switchers }\end{array}$ \\
\hline
\end{tabular}

aNumbers in the parentheses represent $p$ values.

bThe differences between group means were all significant at the $p=.05$ level.

TABLE 3

Exploratory Factor Analysis Results for Satisfaction Items

\begin{tabular}{|c|c|c|c|c|}
\hline Items & $\begin{array}{l}\text { People } \\
\text { Factor }\end{array}$ & $\begin{array}{l}\text { Locational } \\
\text { Convenience }\end{array}$ & $\begin{array}{c}\text { Ease of } \\
\text { Transaction }\end{array}$ & Cost \\
\hline The friendliness of the bank employees & .910 & .037 & -.005 & .112 \\
\hline How well the bank managers know me & .842 & .006 & .005 & .183 \\
\hline How well the bank listens to my needs & .939 & .025 & .016 & .016 \\
\hline The quality of service offered by the bank & .890 & .080 & .034 & .117 \\
\hline How close the bank is to my home & .057 & .791 & .209 & -.056 \\
\hline How close the bank is to my place of employment & -.001 & .914 & .100 & .016 \\
\hline How convenient the bank is to my route to work & .067 & .905 & .089 & .004 \\
\hline The number of ATM machines the bank has around town & -.024 & .241 & .689 & -.167 \\
\hline How many tellers are available during busy times & .064 & .090 & .871 & .068 \\
\hline How convenient the banking hours are & -.004 & .072 & .850 & .064 \\
\hline The cost of a checking account & .301 & -.027 & -.006 & .937 \\
\hline Eigenvalue & 3.31 & 2.36 & 2.02 & 1.07 \\
\hline
\end{tabular}

TABLE 4

Exploratory Factor Analysis Results for Involvement Items

\begin{tabular}{|c|c|c|}
\hline Items & $\begin{array}{l}\text { Purchase } \\
\text { Involvement }\end{array}$ & $\begin{array}{l}\text { Ego } \\
\text { Involvement }\end{array}$ \\
\hline I constantly compare the prices and rates offered by various banks in my area. & .796 & -.040 \\
\hline $\begin{array}{l}\text { I visited multiple banks in the area before I opened an account with the current bank. } \\
\text { I compared the prices and rates of several banks in my area before I selected }\end{array}$ & .887 & .046 \\
\hline my current bank. & .858 & -.004 \\
\hline After deciding on my current bank, I have discussed my choice with family and friends. & .551 & .125 \\
\hline $\begin{array}{l}\text { After deciding on my current bank, I have compared my bank with other banks in } \\
\text { the area. }\end{array}$ & .726 & -.084 \\
\hline After deciding on my current bank, I have weighed the pros and cons of my choice. & .632 & .093 \\
\hline $\begin{array}{l}\text { The brand image of the bank played a major role in my decision to become a customer } \\
\text { of the bank. }\end{array}$ & .053 & .632 \\
\hline The bank I use says a lot about who I am. & .031 & .822 \\
\hline It is important for me to choose a bank that "feels" right. & -.009 & .795 \\
\hline Eigenvalue & 3.39 & 1.74 \\
\hline
\end{tabular}


Active Loyalty Behavior

I would highly recommend my bank to my friends and family.

I am likely to make negative comments about my bank to my friends and family.

In the near future, I intend to use more of the services offered by my bank.

If my current bank were to raise the price of my checking account, I would still continue to be a customer of the bank.

If a competing bank were to offer a better rate or discount on their services, I would switch.

As long as I live in this neighborhood, I do not foresee myself switching to a different bank.
.864

$-.823$

614

$-.007$

.060

.057
Passive Loyalty Behavior

Eigenvalue

1.81

.137

$-.046$

$-.160$

.787

$-.753$

.732

1.77 same six factors being a part of the final solution. (For the sake of brevity, the results of the stepwise analysis are not reported here.)

The first function accounts for $64 \%$ of the total variance explained, and the second function explains $36 \%$ of the remaining variance. The squared canonical correlations are .40 and .27 , respectively, for the two functions. The value of the Wilks' lambda is .43 and is significant at $p<.01$. Furthermore, the hit ratios for the analysis sample (72.8\%) and the holdout sample $(70.0 \%)$ are above the proportional chance criterion (of 42.8\%), and the corresponding Press Qstatistic is significant at the .01 level for both the analysis and the holdout sample. Table 6 also presents group means for all eight criterion variables.

\section{Satisfaction with the Individual Dimensions of the Service}

The hypotheses pertaining to customers' satisfaction with the individual aspects of the banking service state that satisfaction with the people factor of the service will be a stronger discriminant of the three groups of customers than satisfaction with other aspects of the service. As mentioned previously, the factor analysis of the 11 items relating to the key attributes of the banking service revealed a four-factor solution: the people factor, locational convenience, ease of transaction, and cost. Thus, support for this hypothesis requires that the discriminant analysis results reveal that the people factor is significantly better in discriminating among the three groups than the other three factors.

The results, illustrated in Table 6 , reveal that only two of the four factors are significant in discriminating among the groups: the people and the cost factors. Furthermore, an examination of the discriminant loadings, standardized coefficients, and potency index suggests that the influence of the people factor on the discriminant function is stronger than the influence of the cost factor. Finally, as is shown in Table 6, the group means suggest that as in the case of the overall satisfaction variable, the mean satisfaction level decreases from the dissatisfied switchers to stayers to the satisfied switchers. This provides support for $\mathrm{H}_{3}$.

\section{Purchase and Ego Involvement}

$\mathrm{H}_{4}$ states that the dissatisfied switchers exhibit higher levels of purchase involvement than the satisfied switchers. Likewise, $\mathrm{H}_{5}$ states that the switchers exhibit lower levels of ego involvement than the stayers, and $\mathrm{H}_{6}$ states that the dissatisfied switchers exhibit lower levels of ego involvement than the satisfied switchers. Support for these hypotheses requires that (1) the overall discriminant function is significant, (2) both purchase and ego involvement factors are significant in discriminating among the three groups, and (3) the group means are in the hypothesized directions.

Table 6 reveals that both purchase and ego involvement are significant in discriminating among the groups and that the group means are in the hypothesized direction. Also, an examination of the discriminant loadings and standardized coefficients suggests that the impact of ego involvement on the discriminant function is stronger than the influence of purchase involvement. This provides support for $\mathrm{H}_{4}, \mathrm{H}_{5}$, and $\mathrm{H}_{6}$.

\section{Customer Loyalty}

$\mathrm{H}_{7}$ and $\mathrm{H}_{8}$ pertain to group differences with regard to the groups' loyalty toward the bank, stating that the dissatisfied switchers are more loyal to their current service provider than the other two groups. In addition, a comparison of the satisfied switchers and the stayers reveals that the former is less loyal. As mentioned previously, factor analysis performed on the six items measuring the loyalty construct revealed a two-factor solution: active and passive loyalty.

Therefore, support for these hypotheses requires that (1) the overall discriminant function is significant, (2) both active and passive loyalty factors are significant in discriminating among the three groups, and (3) the group means are in the hypothesized directions; that is, the dissatisfied switchers are the most loyal, followed by the stayers and finally the satisfied switchers.

Table 6 reveals that both active and passive loyalty factors are significant in discriminating among the groups. Furthermore, an examination of the potency index suggests that active and passive loyalty have almost equal influence on the discriminant function. But an examination of the group means reveals that whereas the means are in the hypothesized direction for active loyalty, such is not the case for 


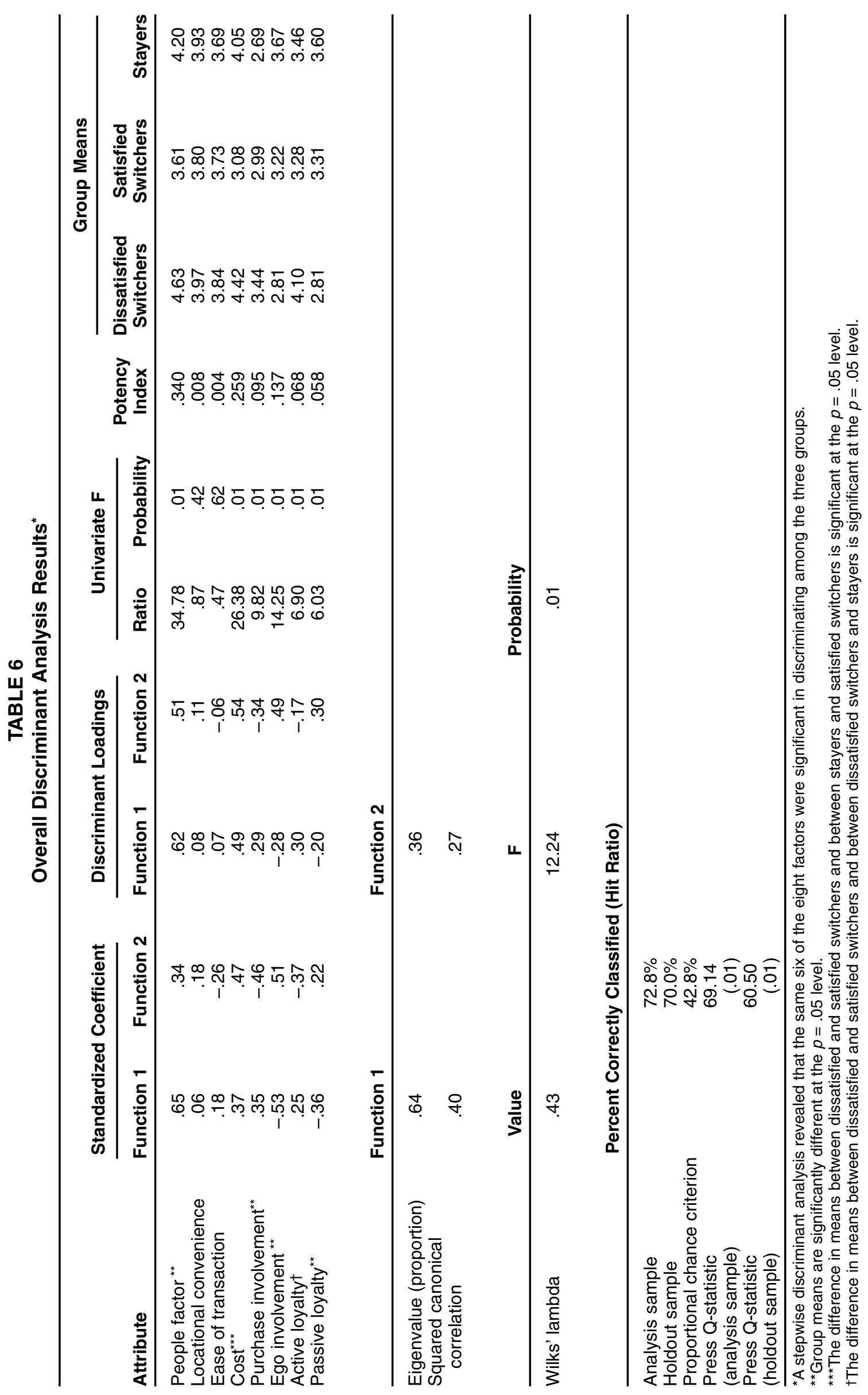


passive loyalty. The dissatisfied switchers are not higher in passive loyalty than the other groups. Indeed, they exhibit the lowest levels of passive loyalty. The group means indicate that the stayers exhibit the highest passive loyalty, followed by the satisfied switchers and finally the dissatisfied switchers. This finding thus provides only partial support for $\mathrm{H}_{7}$ and $\mathrm{H}_{8}$. The implications of this finding are discussed subsequently.

Finally, to check for differences based on the duration of stay with the current service provider, we split the groups into two (less than five years and more than five years). A test of group means revealed no significant difference in satisfaction, loyalty, and involvement measures for all three groups of customers. The small size of the subgroups (particularly the dissatisfied switchers and the stayers) prevented us from using duration of stay as a continuous variable in the analysis.

\section{Premise for Study 2}

Although the findings of Study 1 that support the hypotheses offer rich academic and managerial implications, some other relevant issues, if explored, have the potential to offer further insights in this area. First, given our focus on a service industry in one geographic location, replication in a larger sample would help establish the external validity of these findings. Second, Study 1 reveals some interesting results regarding the influence of past switching behavior on subsequent satisfaction levels, but it provides little insight regarding (1) the relevant time frame in which these effects are likely to operate or (2) the effects of any prior switches on current satisfaction levels. Finally, although we defined and tested these three distinct customer groups on the basis of their switching or a lack of switching experience, we have little knowledge as to the potential differences within these three customer groups in terms of other relevant variables, such as commitment, dependence, and risk aversion.

Therefore, we conducted Study 2 with the objective of replicating the findings of Study 1 and offering some theoretical and empirical insights on the abovementioned issues. It is imperative to state here that the issues addressed here have not been fully explored in the literature and warrant the undivided attention of a broader research study. Therefore, we treat these issues here as largely exploratory and make a first attempt to understand these relationships and provide some guidelines for further research that focuses on these issues in greater breadth and depth. We now discuss each of these three issues in greater detail.

\section{Duration of Stay}

The literature suggests that time influences expectations and satisfaction in several important ways. Research investigating expectations in satisfaction and service quality evaluations suggests that as time spent as a customer with the provider increases, the expectations used as a basis of comparison tend to adjust to the new service provider. For example, Boulding and colleagues (1993) argue that consumers' current perceptions of service quality of a firm just after a service contact are in part influenced by their prior expectations of what will and what should transpire during the contact. They argue that over time, will expectations are updated with each new service encounter and prior will expectations. Applied here, this suggests that for satisfaction judgments arrived at through the expectancy-disconfirmation paradigm, it is expected that customers adapt over time to the new levels of service provided by the switched-to firm.

Furthermore, researchers have also suggested that with the passage of time, customers are more likely to employ similar types of expectations. For example, Woodruff, Cadotte, and Jenkins (1983) theorize that customers with extensive brand experience are more likely to employ focal brand expectations than customers with limited brand experience, who in turn are more likely to employ experiencebased norms. The implication of this research is that as tenure with the brand (or firm) increases, customers are likely to employ common sets of expectations (focal brand), with the effect of mitigating large discrepancies in satisfaction scores early in their tenure with the firm. These arguments lead us to pose the following question:

\section{$\mathrm{RQ}_{1}$ : Do the differences among the three groups in terms of their overall level of satisfaction change with increasing tenure with the switched-to bank?}

More generally, is there a relationship between duration of stay with the current bank and a customer's overall satisfaction with the bank? Theory generally does not provide specific guidance regarding the relevant time frames in which the hypothesized relationships are supposed to operate. Although we found no significant difference among the groups based on duration of stay (five years), further investigation with an adequate sample size would be particularly useful in providing insights into this important and relevant issue on postswitching behavior.

\section{Mixed Switching Experiences}

In addition to the effects of duration of stay on levels of satisfaction, the literature suggests that differences also exist in satisfaction with the current bank among customers with multiple switching experiences. Research in memory recall bias (Folkes 1994) and heuristic processing (Tversky and Kahneman 1974) suggests that the most emotionally charged and atypical experiences are likely to play a large role in establishing future comparison standards. For example, Folkes $(1988,1994)$ notes that past experiences that are distinctive and easily distinguished from others are likely to be sampled more readily by consumers when they recall service experiences and establish expectations. This is particularly true when consumers elaborate on such distinctive events and attach strong affective traces to these memories. Even when consumers have difficulty recalling specific events or are not motivated to do so, heuristic processing that relies on recalling past service exemplars is often employed. In the current context, a dissatisfied switch is assumed to be more emotionally taxing than a satisfied switch, which would then imply that a dissatisfied switch (irrespective of when it occurred) might be the most salient one.

In contrast, recency bias suggests that the most recent switching event plays an influential role in establishing the comparison standards for the current service experience. Essentially, recency bias suggests that people are more likely to recall more recent events than more distant ones 
(Crano 1977; Greene 1986; Pieters and Bijmolt 1997). This occurs in part because of retroactive interference (Burke and Srull 1988) and context-dependent (Greene 1986) memory processes, as well as because more recent events/memories are easier to discriminate (Crowder 1976). In this study, recency bias suggests that the more recent switching experience is likely to be given more weight in developing future expectancies, irrespective of whether the most recent switch was a dissatisfied or a satisfied switch.

In summary, recency bias theory suggests that the most recent service experience plays a dominant role in establishing future expectancies. In contrast, research in memory recall bias and heuristic processing suggests that the most emotionally taxing and distinctive service experience plays a major role in establishing future expectancies. Although Study 1 provides evidence that the three customer groups identified in this study differ significantly in their satisfaction with the current service provider on the basis of their most recent switching experience (or lack thereof), we have no information on the motivations for any previous switches and their possible impact on the current level of satisfaction. In simple terms, in a two-switch sequence, does the reason for switching from the bank at time $\mathrm{t}-2$ to the bank at time $\mathrm{t}-1$ influence customers' satisfaction with their current bank (bank at time t)?

We classify customers as satisfied switchers or dissatisfied switchers on the basis of their most recent switching experience and report that on average, the dissatisfied switchers exhibit a higher level of satisfaction with the current service provider than the satisfied switchers. However, the customers classified as satisfied switchers on the basis of their most recent switching experience could have switched previously because of either dissatisfaction or satisfaction. The same is true for those customers classified as dissatisfied switchers. It would be interesting to know whether the reasons for any prior switches play a role in influencing the satisfaction with the current service provider. In other words, are there differences in satisfaction levels within the satisfied switcher group based on their previous switching experiences? The same question can be asked of the dissatisfied switchers. Such an analysis would provide us with some insight as to which switch, the most recent or the most emotionally taxing, is the most salient regarding comparison levels employed with the current service provider. Hence, we formulate our second research question:

$\mathrm{RQ}_{2}$ : Are there differences in the current levels of satisfaction among customers with mixed switching experiences?

\section{Within-Group Differences Based on Other Rele- vant Variables}

Finally, although Study 1's results show that the three groups based on the switching behavior differ in terms of their satisfaction and involvement with and loyalty toward the bank, there could exist subgroups within these three homogeneous groups that differ in terms of other relevant variables. An understanding of these differences (if any) within the groups would provide some insights into how the subgroups differ in terms of their satisfaction, involvement, and loyalty behaviors.

Prior research on maintaining customer relationships (e.g., Bendapudi and Berry 1997; Morgan and Hunt 1994), as well as related research on switching behavior (e.g., Raju 1980), suggests that the constructs of dependence, commitment, and risk aversion are particularly important for better understanding the reasons customers stay with a firm. Dependence and commitment have been associated with several critical outcomes (Ganesan 1994; Morgan and Hunt 1994) and reflect fundamental differences in the way a customer views an ongoing relationship (Bendapudi and Berry 1997). Risk aversion reflects a general exploratory tendency that is relevant to understanding a customer's propensity to switch or stay for intrinsic reasons (Raju 1980). We briefly review each of these three constructs.

First, customers exhibiting high levels of commitment are more likely to maintain a dedication-based relationship, in which customers are motivated to maintain the relationship because they genuinely want to (Bendapudi and Berry 1997; Morgan and Hunt 1994). Customers who are highly committed to an ongoing relationship are also likely to seek greater relationship expansion and enhancement, identify strongly with the partner, view such a relationship as a team, engage in behaviors such as open advocacy of the partner (Bendapudi and Berry 1997), cooperate with the partner, and stay in the relationship (Morgan and Hunt 1994). Therefore, commitment appears to be an influential variable on several attitudinal and behavioral variables measured here.

Second, customers who are highly dependent on a relationship are more likely to maintain a constraint-based relationship, or a relationship in which customers believe that they must remain in the relationship, not that they want to (Bendapudi and Berry 1997). Constraint-based relationships lead to preservation of the relationship only as long as the perceived constraints exist (Bendapudi and Berry 1997). Customers high in dependence are more likely to acquiesce to the partner's requests or policies and, in line with reactance theory (Brehm 1966), actively seek alternatives (Bendapudi and Berry 1997).

Third, customers who are particularly risk averse are less likely to take risks or be adventurous (Raju 1980). Risk aversion/risk taking has long been viewed as a manifestation of human exploratory behavior, such that the amount of risk a consumer is willing to take in a choice situation is seen as a larger effort to adjust the level of actual stimulation to the optimal level (Baumgartner and Steenkamp 1996; Berlyne 1960; Raju 1980). Prior research has supported the notion that being loyal to a brand is a strategy consumers employ to control the risk inherent in certain buying situations (e.g., Arndt 1968). Therefore, customers high in risk aversion are likely to exhibit differences in loyalty toward the current service provider compared with customers who are less risk averse. Taken together, the evidence from research on dependence, commitment, and risk aversion provides the basis for the following research question:

$\mathrm{RQ}_{3}$ : Are there subgroups within the three main customer groups that differ in terms of commitment, dependence, and risk aversion, and if so, do they exhibit significant differences in their overall satisfaction, involvement, and loyalty behaviors?

We first discuss the data collection process involved in the second study and then discuss the results of the replication analyses. Subsequently, we report the results of the 
analyses conducted to investigate each of the three research questions. Following this, we discuss our findings from both studies, offer theoretical and practical implications, and discuss limitations and future research opportunities.

\section{Study 2: Instrument Design, Data Collection, and Preliminary Analyses}

As mentioned previously, we conducted Study 2 to replicate the findings of Study 1 and to address other interesting issues. Again, we used a telephone interview method to collect the data and adopted all the screening procedures used in the first study. However, in the second study we used a random-digit dialing approach to identify potential respondents located in the Northeast and the Southwest regions of the United States.

In total, 6678 calls were made; 1763 of these were made to businesses, government entities, or nonworking numbers, and 376 calls reached either fax machines or modems. The number of calls that resulted in no answer, received a busy signal, reached an answering machine, or resulted in no contact after two callback attempts totaled 2227. Furthermore, 171 calls were terminated because of language barriers, and 1331 potential respondents refused to participate before they were qualified. Of the potential respondents, 193 did not qualify, whereas 16 others qualified but then refused. Also, 65 calls resulted in a midcall termination. In all, completed responses totaled 536. However, 42 surveys were unusable because of missing values. Thus, the total number of usable surveys was 494, which yielded an effective response rate of $27.5 \%$ (536/1948). A preliminary analysis of the data revealed ample variance in the responses for all items measured. Moreover, the demographic profile of respondents in Study 2 was found to be similar to that of Study 1 . In Table 7, we present a comparative demographic profile of the samples used in both studies.

The measurement instrument contained all the items used in Study 1, and we added new items that measured sev-

TABLE 7

A Comparison of the Demographic Profiles of Studies 1 and 2

\begin{tabular}{|c|c|c|c|c|}
\hline \multirow[b]{2}{*}{ Variable } & \multicolumn{2}{|c|}{ Sample 1} & \multicolumn{2}{|c|}{ Sample 2} \\
\hline & Frequency & $\%$ & Frequency & $\%$ \\
\hline \multicolumn{5}{|l|}{ Sex } \\
\hline Male & 102 & $51.5 \%$ & 226 & $45.7 \%$ \\
\hline Female & 96 & $48.5 \%$ & 268 & $54.3 \%$ \\
\hline \multicolumn{5}{|l|}{ Marital Status } \\
\hline Single & 51 & $27.4 \%$ & 115 & $23.5 \%$ \\
\hline Married & 116 & $62.4 \%$ & 268 & $54.8 \%$ \\
\hline Separated & 2 & $1.1 \%$ & 18 & $3.7 \%$ \\
\hline Divorced & 7 & $3.8 \%$ & 47 & $9.6 \%$ \\
\hline Widowed & 10 & $5.4 \%$ & 41 & $8.4 \%$ \\
\hline \multicolumn{5}{|l|}{ Age } \\
\hline$<19$ years & 7 & $3.5 \%$ & 5 & $1.0 \%$ \\
\hline $19-25$ years & 37 & $18.8 \%$ & 48 & $9.9 \%$ \\
\hline $26-35$ years & 48 & $24.4 \%$ & 96 & $19.8 \%$ \\
\hline $36-45$ years & 41 & $20.8 \%$ & 117 & $24.1 \%$ \\
\hline $46-55$ years & 38 & $19.3 \%$ & 107 & $22.1 \%$ \\
\hline $56-65$ years & 16 & $8.1 \%$ & 49 & $10.1 \%$ \\
\hline$>65$ years & 10 & $5.1 \%$ & 63 & $13.0 \%$ \\
\hline \multicolumn{5}{|l|}{ Household Income } \\
\hline$<\$ 20,000$ & 19 & $13.3 \%$ & 26 & $6.3 \%$ \\
\hline$\$ 20,000-35,000$ & 36 & $25.2 \%$ & 88 & $21.5 \%$ \\
\hline$\$ 35,001-50,000$ & 36 & $25.2 \%$ & 107 & $26.1 \%$ \\
\hline$\$ 50,001-100,000$ & 41 & $28.7 \%$ & 124 & $30.2 \%$ \\
\hline$>\$ 100,000$ & 11 & $7.7 \%$ & 65 & $15.8 \%$ \\
\hline \multicolumn{5}{|l|}{ Education } \\
\hline Less than high school & 4 & $2.2 \%$ & 16 & $3.3 \%$ \\
\hline High school graduate & 34 & $18.6 \%$ & 92 & $18.9 \%$ \\
\hline Technical school & 8 & $4.4 \%$ & 32 & $6.6 \%$ \\
\hline Some college & 33 & $18.0 \%$ & 129 & $26.4 \%$ \\
\hline College graduate & 86 & $47.0 \%$ & 136 & $27.9 \%$ \\
\hline Postgraduate & 18 & $9.8 \%$ & 83 & $17.0 \%$ \\
\hline
\end{tabular}


eral other constructs to investigate the issues mentioned previously. First, in addition to measuring the reasons for switching from the previous bank (i.e., the bank at time $\mathrm{t}-$ 1) to the current bank (i.e., the bank at time t), we measured respondents' reasons for switching from their bank at time $\mathrm{t}-2$ to the bank at time $\mathrm{t}-1$. Also, we measured respondents' overall satisfaction with their previous bank (time t1) and the duration of stay (in years) at the current and previous banks.

Second, to address $\mathrm{RQ}_{3}$, we included three additional measures in Study 2: dependence on the current bank, commitment to the current bank, and risk aversion. We measured all three constructs using established scales from the literature. The measure for commitment, based on a scale used by Morgan and Hunt (1994), contained three items: (1) "The relationship that I share with my bank is something that the bank and I are very committed to," (2) "The relationship that I share with my bank is something that is very important to me," and (3) "The relationship that I share with my bank is something that deserves my maximum effort to maintain." The scale measuring dependence, adapted from a measure employed by Ping (1993), included the following three items: (1) "In general, it would be a hassle changing banks," (2) "It would take a lot of time and effort changing banks," and (3) "For me, the emotional and financial costs of switching banks are high."

Finally, we measured risk aversion using items adapted from a scale used by Raju (1980): (1) "I am very cautious in trying new/different products," (2) "I would rather stick with a brand I usually buy than try something I am not very sure of," and (3) "I enjoy taking chances in buying unfamiliar brands just to get some variety in my purchases." All three constructs comprised only three items to keep the questionnaire to a reasonable length, and we measured them on a five-point Likert scale that ranged from "strongly disagree" to "strongly agree." We then factor analyzed these nine items, and a scree plot of the eigenvalues revealed a clean three-factor solution. All items loaded highly on the appropriate factor, and there were no significant cross-loadings. Furthermore, the coefficient alphas for the items loading on the commitment, dependence, and risk aversion factors are .82, .76, and .74, respectively, which indicates an acceptable level of reliability (Nunnally 1978).

\section{Study 2 Results 1}

Replication of Study 1. To test $\mathrm{H}_{1}$ and $\mathrm{H}_{2}$, we used ANOVA to compare group means on the overall satisfaction item obtained from the larger sample. The results, shown in Table 8, reveal that the groups are significantly different with regard to their overall satisfaction with their current bank. Furthermore, the results show that the mean satisfaction level decreases from the dissatisfied switchers to stayers to satisfied switchers. This provides support for $\mathrm{H}_{1}$ and $\mathrm{H}_{2}$ and replicates the results of Study 1 .

In the same manner as in Study 1, we tested group differences with regard to satisfaction with the individual aspects of the service, involvement, and loyalty. We again factor analyzed the measures of these constructs to determine their measurement properties and dimensionality. For all constructs, the factor solution and item loadings that emerged were similar to those obtained in Study 1 (the results of the factor analyses can be obtained from the authors). Again, we employed multiple discriminant analysis to test $\mathrm{H}_{3}-\mathrm{H}_{8}$. Furthermore, we performed a proportional $50 / 50$ split-sample validation to check the validity of the models. We present the three-group discriminant analysis with all eight factors in Table 9.

\footnotetext{
${ }^{1}$ In addition to validating the findings of Study 1 and empirically examining the issues posed in the research questions, the analyses in Study 2 data reveal some other interesting findings. First, the mean overall satisfaction scores of the satisfied switchers with their previous bank were significantly higher (3.97) than those of the dissatisfied switchers (2.41). This result provides a validity check for classifying the switchers as satisfied and dissatisfied in terms of their switching experience. Second, the satisfied switchers seemed more satisfied with their previous bank (3.97) than with their current bank (3.81). Although this difference is not statistically significant, it is in line with the premise and the arguments presented in this study regarding satisfaction and loyalty behavior of satisfied switchers toward their current bank. Finally, as was mentioned in the discussion of $\mathrm{RQ}_{2}$, only one respondent had switched twice because of dissatisfaction. Although the sample size of one is too small to make any statistical inferences, it suggests that there is no evidence of chronic dissatisfaction among the respondents of this study.
}

TABLE 8

Overall Satisfaction Measure: Difference Between Group Means (Study 2)

\begin{tabular}{|c|c|c|c|c|}
\hline Measure & Groups & Mean Scoresa & $\begin{array}{c}\text { Difference Betwe } \\
\text { Means }^{\mathbf{b}}\end{array}$ & \\
\hline \multirow[t]{3}{*}{$\begin{array}{l}\text { Overall, how satisfied are } \\
\text { you with your bank? }\end{array}$} & $\begin{array}{l}\text { Stayers } \\
(n=203)\end{array}$ & $\begin{array}{l}4.18 \\
(.0001)\end{array}$ & $\begin{array}{l}\text { Stayers versus } \\
\text { satisfied switchers }\end{array}$ & .37 \\
\hline & $\begin{array}{l}\text { Satisfied switchers } \\
\qquad(n=212)\end{array}$ & $\begin{array}{l}3.81 \\
(.0001)\end{array}$ & $\begin{array}{l}\text { Stayers versus } \\
\text { dissatisfied switchers }\end{array}$ & -.40 \\
\hline & $\begin{array}{l}\text { Dissatisfied switchers } \\
\qquad(n=79)\end{array}$ & $\begin{array}{c}4.58 \\
(.0001)\end{array}$ & $\begin{array}{l}\text { Satisfied switchers } \\
\text { versus dissatisfied } \\
\text { switchers }\end{array}$ & -.77 \\
\hline
\end{tabular}

aNumbers in the parentheses represent $p$ values.

bThe differences between group means were all significant at the $p=.05$ level. 


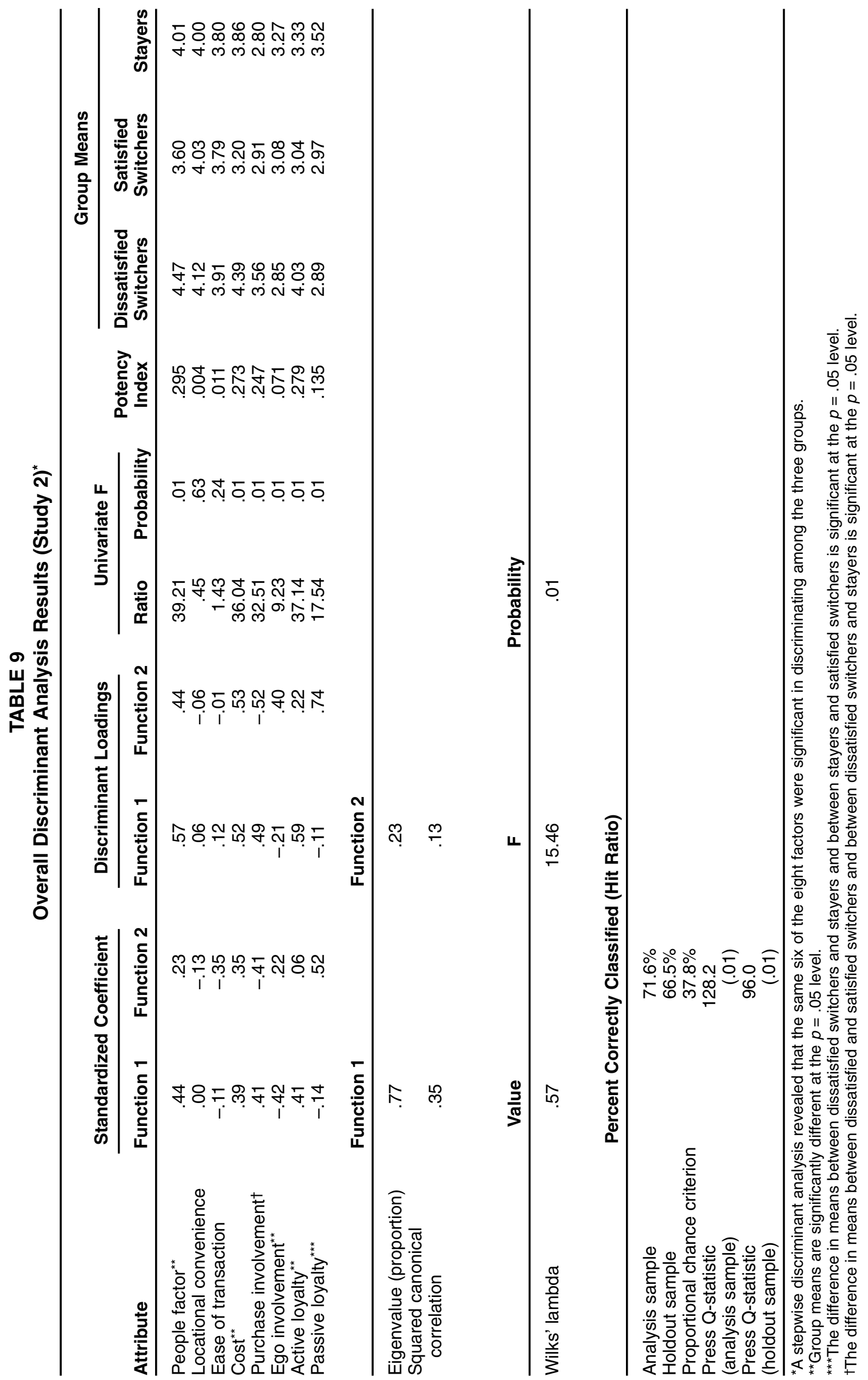


Recall that in Study 1, only two of the four satisfaction factors (the people factor and cost) were significant in discriminating among the groups. In Study 2, as is shown in Table 9, the discriminant analysis results were consistent with this finding. Furthermore, an examination of the potency index suggests that the role of the people (problemsolving) factor is strongest in discriminating among the three groups. In Table 9, we also show that the group means are in the hypothesized direction. Similarly, an examination of Table 9 regarding the roles of purchase involvement, ego involvement, and active and passive loyalty reveals that all four factors are significant in discriminating among the groups and the means are quite similar to those obtained in Study 1. However, in both samples, the dissatisfied switchers exhibit the highest levels of active loyalty. In all, the results of Study 2 replicate the findings of Study 1 closely and thus provide repeated support for $\mathrm{H}_{3}-\mathrm{H}_{8}$.

Duration of stay. To examine whether the differences among the three customer groups in their overall satisfaction with the current bank change with an increase in tenure with the bank, we categorized the respondents into four groups on the basis of their duration of stay with the current bank: (1) one year or less, (2) two to five years, (3) six to ten years, and (4) more than ten years. We tested the difference among the mean overall satisfaction scores for the three groups across the four time periods, and we present the results in Table 10. The results reveal that the mean overall satisfaction score of dissatisfied switchers is significantly different (at the $p=.05$ level) from that of the other two groups for

TABLE 10

Influence of Duration of Stay on Overall Satisfaction Scores

\begin{tabular}{lccc}
\hline Time Period & $\begin{array}{c}\text { Dissatisfied } \\
\text { Switchers }\end{array}$ & $\begin{array}{c}\text { Satisfied } \\
\text { Switchers }\end{array}$ & Stayers \\
\hline $\begin{array}{c}\text { One year } \\
\text { and less* }\end{array}$ & $\begin{array}{c}4.87 \\
(\mathrm{n}=15)\end{array}$ & $\begin{array}{c}3.63 \\
(\mathrm{n}=43)\end{array}$ & $\begin{array}{c}4.10 \\
(\mathrm{n}=20)\end{array}$ \\
$\begin{array}{c}\text { Two to five } \\
\text { years* }\end{array}$ & $\begin{array}{c}4.62 \\
(\mathrm{n}=24)\end{array}$ & $\begin{array}{c}3.69 \\
(\mathrm{n}=65)\end{array}$ & $\begin{array}{c}4.31 \\
(\mathrm{n}=42)\end{array}$ \\
$\begin{array}{c}\text { Six to ten } \\
\text { years* }\end{array}$ & $\begin{array}{c}4.60 \\
(\mathrm{n}=20)\end{array}$ & $\begin{array}{c}4.00 \\
(\mathrm{n}=52)\end{array}$ & $\begin{array}{c}4.09 \\
(\mathrm{n}=45)\end{array}$ \\
$\begin{array}{c}\text { More than } \\
\text { ten years }\end{array}$ & $\begin{array}{c}4.30 \\
(\mathrm{n}=20)\end{array}$ & $\begin{array}{c}3.87 \\
(\mathrm{n}=52)\end{array}$ & $\begin{array}{c}4.21 \\
(\mathrm{n}=96)\end{array}$ \\
\hline
\end{tabular}

${ }^{*}$ The difference in the mean score between dissatisfied switchers and the other two groups is significant at the $p=.05$ level. the first three time periods and is not significantly different for the fourth time period. Moreover, the overall satisfaction with the current bank seems to decline with time for dissatisfied switchers, from a high of 4.87 for those who had spent one year or less with the bank to 4.30 for dissatisfied switchers who have been with the current bank for more than ten years. Furthermore, no significant discernible patterns could be observed in the overall satisfaction scores of the other two groups over time.

Mixed switching experiences. To uncover the precise nature of the customers who have multiple switching experiences, we collected data on the reasons for switching for the two previous switching events. Of the total sample of 494 respondents, 79 were dissatisfied switchers, 212 were satisfied switchers, and 203 were stayers. Thus, 291 respondents had switched from their bank at time $\mathrm{t}-1$ to the current bank at time $\mathrm{t}(79+212)$. Of the 291 , only 92 had switched banks once before (i.e., from the bank at time $\mathrm{t}-2$ to the bank at time $\mathrm{t}-1$ ). Two did not respond to the question regarding the reason for switching from $t-2$ to $t-1$.

Analysis revealed that of the sample of mixed-experience switchers $(n=90)$, the mean overall satisfaction score (with the current bank) for customers who reported a dissatisfied switch followed by a dissatisfied switch was $5.00(\mathrm{n}=$ 1). For customers who reported a satisfied switch followed by a dissatisfied switch, the mean was $4.81(\mathrm{n}=21)$. Likewise, the mean for customers who reported a dissatisfied switch followed by a satisfied switch was $4.23(\mathrm{n}=13)$, and the mean for customers who reported a satisfied switch followed by a satisfied switch was $3.76(n=55)$.

An ANOVA conducted on the sample of mixed-experience switchers $(n=90$; overall $F=5.46)$ revealed significant differences (at the $p=.05$ level) only between the second and fourth groups, that is, between the satisfied $\rightarrow$ dissatisfied and the satisfied $\rightarrow$ satisfied customers. Furthermore, we reanalyzed this data after removing the one respondent who indicated a dissatisfied $\rightarrow$ dissatisfied sequence and found nearly identical results $(F=7.81$, mean scores identical, same groups significantly different). In Table 11, we present the results of the analysis.

The results reveal no significant difference in the mean overall satisfaction scores of mixed-experience customers who are similarly classified currently as either dissatisfied switchers (i.e., between the dissatisfied $\rightarrow$ dissatisfied and the satisfied $\rightarrow$ dissatisfied groups) or satisfied switchers (i.e., between the dissatisfied $\rightarrow$ satisfied and the satisfied $\rightarrow$ satisfied groups). Although the sample size precluded the inclusion of duration of stay with the current or previous

TABLE 11

Testing the Effects of Prior Switching Experiences on Satisfaction with Current Bank

\begin{tabular}{|c|c|c|c|c|}
\hline $\begin{array}{l}\text { Reason for Switching } \\
\text { from Bank at }(t-2) \\
\text { to Bank at }(t-1)\end{array}$ & $\begin{array}{l}\text { Reason for Switching } \\
\text { from Bank at }(\mathrm{t}-1) \\
\text { to Current Bank (t) }\end{array}$ & $\begin{array}{l}\text { Mean Current } \\
\text { Satisfaction } \\
\text { Score }\end{array}$ & $\mathbf{n}$ & $\begin{array}{c}\text { Current Switching } \\
\text { Classification }\end{array}$ \\
\hline Dissatisfied & Dissatisfied & 5.00 & 1 & Dissatisfied switcher \\
\hline $\begin{array}{l}\text { Satisfied } \\
\text { switcher* }\end{array}$ & Dissatisfied & 4.81 & 21 & Dissatisf \\
\hline Dissatisfied & Satisfied & 4.23 & 13 & Satisfied switcher \\
\hline Satisfied & Satisfied & 3.76 & 55 & Satisfied switcher* \\
\hline
\end{tabular}


banks in the analysis, the empirical evidence presented here suggests that the most recent switching experience is more likely to influence the comparison standard used by the switchers and therefore their satisfaction with and loyalty behavior toward the current service provider. However, these findings are preliminary, and further research is needed to examine this issue in greater detail.

Within-group differences based on other relevant variables. The final issue examined in Study 2 involved possible differences within the three customer groups with regard to their overall satisfaction and involvement with and loyalty toward the current bank. As mentioned previously, we tested the differences within the three groups on three key constructs-commitment, dependence, and risk aversion-to identify and explain any differences within the groups. First, we divided the dissatisfied switchers, the satisfied switchers, and the stayers into two groups each on the basis of their scores on commitment to their current bank using a mean split: high commitment versus low commitment. Second, we tested the difference in the mean satisfaction, involvement, and loyalty scores of the high- and low-commitment groups for each of the three customer groups. The analysis revealed that the satisfaction levels of the customers exhibiting high commitment within each of the three groups were significantly higher than those of customers exhibiting low commitment. The results were more mixed for the other constructs: purchase involvement, ego involvement, active loyalty, and passive loyalty. However, no significant differences were found within each of the three groups in terms of high and low dependence and risk aversion.

In Table 12, we present the results of the analyses conducted to test for differences between high- and low-commitment customers within the three hypothesized groups. The results reveal some interesting within-group differences, the implications of which are discussed subsequently.

\section{Discussion and Implications}

Effectively targeting customers with loyalty and retention programs implies some level of knowledge about these people, both stayers and new customers who have switched from other service providers. The research presented here provides a much-needed perspective on customers who switch and how they differ among themselves (depending on why they switch) and from stayers in terms of satisfaction, involvement, and loyalty. The findings and contribution of this research include the following:

1. It confirms the presence of the a priori hypothesized groups in the customer base of a typical service provider.

2. It shows that these three groups differ significantly in terms of their satisfaction with the current service provider, pur-

TABLE 12

Within-Group Differences Based on Commitment to Service Provider

\begin{tabular}{|c|c|c|c|c|}
\hline Variable & & Dissatisfied Switchers & Satisfied Switchers & Stayers \\
\hline \multirow[t]{2}{*}{$\begin{array}{l}\text { Overall } \\
\text { satisfaction }\end{array}$} & $\mathrm{HC}^{*}$ & $\begin{array}{l}4.71^{\star *} \\
(n=55)\end{array}$ & $\begin{array}{c}4.17^{\star \star} \\
(n=107)\end{array}$ & $\begin{array}{c}4.49^{* \star} \\
(n=111)\end{array}$ \\
\hline & LC & $\begin{array}{c}4.29 \\
(n=24)\end{array}$ & $\begin{array}{c}3.42 \\
(n=105)\end{array}$ & $\begin{array}{l}3.84 \\
(n=92)\end{array}$ \\
\hline \multirow[t]{2}{*}{$\begin{array}{l}\text { Purchase } \\
\text { involvement }\end{array}$} & $\mathrm{HC}$ & $\begin{array}{c}3.61 \\
(n=55)\end{array}$ & $\begin{array}{c}3.08^{* \star} \\
(n=104)\end{array}$ & $\begin{array}{c}2.89 \\
(n=109)\end{array}$ \\
\hline & LC & $\begin{array}{c}3.43 \\
(n=23)\end{array}$ & $\begin{array}{c}2.73 \\
(n=104)\end{array}$ & $\begin{array}{l}2.69 \\
(\mathrm{n}=88)\end{array}$ \\
\hline \multirow[t]{2}{*}{$\begin{array}{l}\text { Ego } \\
\text { involvement }\end{array}$} & $\mathrm{HC}$ & $\begin{array}{l}3.00^{\star *} \\
(n=55)\end{array}$ & $\begin{array}{c}3.39^{* *} \\
(n=103)\end{array}$ & $\begin{array}{c}3.65^{\star \star} \\
(n=106)\end{array}$ \\
\hline & LC & $\begin{array}{c}2.49 \\
(n=23)\end{array}$ & $\begin{array}{c}2.76 \\
(n=101)\end{array}$ & $\begin{array}{l}2.81 \\
(\mathrm{n}=87)\end{array}$ \\
\hline \multirow[t]{2}{*}{ Active loyalty } & $\mathrm{HC}$ & $\begin{array}{c}4.07 \\
(n=55)\end{array}$ & $\begin{array}{c}3.34^{\star \star} \\
(n=107)\end{array}$ & $\begin{array}{c}3.61^{* *} \\
(n=109)\end{array}$ \\
\hline & LC & $\begin{array}{c}3.93 \\
(n=23)\end{array}$ & $\begin{array}{c}2.75 \\
(n=105)\end{array}$ & $\begin{array}{l}2.98 \\
(n=90)\end{array}$ \\
\hline \multirow[t]{2}{*}{ Passive loyalty } & $\mathrm{HC}$ & $\begin{array}{c}3.11^{* *} \\
(n=52)\end{array}$ & $\begin{array}{c}3.25^{\star *} \\
(n=105)\end{array}$ & $\begin{array}{c}3.60 \\
(n=110)\end{array}$ \\
\hline & LC & $\begin{array}{c}2.42 \\
(n=24)\end{array}$ & $\begin{array}{c}2.68 \\
(n=103)\end{array}$ & $\begin{array}{c}3.42 \\
(n=92)\end{array}$ \\
\hline
\end{tabular}

${ }^{*} \mathrm{HC}=$ high-commitment group; LC = low-commitment group.

${ }^{*}$ The difference in mean scores between the high- and low-commitment groups is significant at the $p=.05$ level. 
chase and ego involvement processes, and loyalty toward the service provider. The results indicate that dissatisfied switchers are the most satisfied customers and are most likely to engage in active loyalty behaviors, whereas stayers, who exhibit higher satisfaction than satisfied switchers but lower satisfaction than the dissatisfied switchers, are more likely to exhibit passive loyalty behaviors. Satisfied switchers are the least satisfied customers and fall between the other two groups in terms of both active and passive loyalty behaviors.

3. It replicates the research results of Study 1 in a larger sample obtained from two geographical regions, which thus provides external validation of the findings.

4. It empirically examines the impact of duration of stay with the current bank on a customer's overall satisfaction with the bank. The results suggest that the difference observed in the overall satisfaction scores among the three groups decreases with increasing tenure with the switched-to bank.

5. It investigates the impact of prior switching experiences on satisfaction with the current service provider. The results suggest that irrespective of the reasons for the prior switches, the most recent switching experience is the most salient for predicting customer satisfaction with the current service provider.

6. It identifies differences within the three hypothesized groups in terms of their commitment to the current service provider.

\section{Implications}

A different perspective on customer loyalty behaviors. Active loyalty behavior can be defined as customers' proactive behaviors or behavioral intentions that require conscious and deliberate effort to undertake. Although initiation of these behaviors does not appear to require changes in the service relationship or service environment, these behaviors may exceed mere repeat patronage to include positive word of mouth and expansion of service usage. However, passive loyalty behavior entails the elasticity of a customer's behaviors or behavioral intentions to significant changes in the service relationship or service environment. Price insensitivity and self-stated retention have been found here to constitute passive loyalty behavior. Several theoretical explanations can be offered as to why the dissatisfied switchers are more likely to engage in active loyalty behavior, whereas stayers are likely to exhibit higher levels of passive loyalty behavior.

Research on emotions, satisfaction, and cognitive dissonance provides a basis for a better understanding of why dissatisfied switchers are more likely to engage in active loyalty behaviors. First, prior research shows that consumers are likely to engage in more word-of-mouth behavior when they have significant emotional experiences (Westbrook 1987) or increases in satisfaction (Swan and Oliver 1989), both of which are associated with the dissatisfied switchers. Second, dissonance theory suggests that dissatisfied switchers are more likely to experience elevated levels of apprehension (dissonance), even perhaps indefinitely (Oliver 1997), because their prior negative experiences remain in the set of knowable potential outcomes that they perceive as having a nonzero probability of recurrence (see Oliver and Winer 1987). When higher levels of dissonance can be expected in a customer group, higher levels of dissonancereducing activity should also be prevalent-activities that may include the active loyalty behaviors evidenced by the dissatisfied switchers. However, dissonance effects do not necessarily preclude the stayers or other customer groups from engaging in similar active loyalty behaviors.

Research on switching costs and involvement can provide insight as to why stayers are more likely to exhibit stronger passive loyalty. Specifically, the lack of experiential knowledge of competitive offerings can contribute to perceived switching costs, particularly through learningcurve effects (Dick and Basu 1994; Guiltinan 1989). Thus, stayers, by definition, lack experiential knowledge; may be more likely to perceive higher switching costs than the other two groups; and therefore are more likely to remain loyal to a service provider, even under conditions of dissatisfaction (Oliva, Oliver, and MacMillan 1992).

Second, social judgment theory (Sherif, Sherif, and Nebergall 1965) predicts that highly involved people exhibit more negative evaluations of communications from competitors, because high involvement is associated with an extended latitude of rejection of competitive offerings. Because the stayers exhibit both higher ego involvement and higher resistance to competitive pressure, as embodied in their higher passive loyalty, this theoretical explanation may be relevant to these findings.

Potential transition from a heterogeneous to a homogeneous consumer base. Our research provides preliminary evidence that suggests that with an increase in the duration of stay at the current bank, the differences in the overall satisfaction scores among the three groups decrease. In other words, over time all three customer groups exhibit similar levels of satisfaction with the bank.

This empirical evidence, if validated across different service settings, may provide insight into the approximate time frame for predictions made by several major theories (e.g., comparison-level theory, experience-based norms). For example, Woodruff, Cadote and Jenkins (1983) suggest that consumers with extensive experience with the focal brand are more likely to use the focal brand as the basis for expectations. Applied here, this suggests that with the passage of time, all customers who stay with their current bank begin to employ a similar set of expectations based on experience with their current bank. What is not specified by prior research, however, is the specific length of time it takes for this to happen. Further examination of this empirical finding would add a significant dimension to our understanding of switching behavior and customer loyalty. The key lies in determining the specific length of time across several industries.

Considerations in managing the customer groups. Our findings suggest that service firms in the retail banking industry fundamentally are faced with managing three distinct, internal customer groups-dissatisfied switchers, satisfied switchers, and stayers - that differ in their satisfaction with, loyalty toward, and involvement with the firm. What is needed, in light of the research presented here, is an effort to recognize the heterogeneity inherent in a firm's customer base (at least for the first ten years) and treat those segments differently with regard to potential investment strategy. In particular, service firms are faced with some critical questions. First, which of these three customer groups warrant strategic investment? Our results suggest that two customer 
groups - the dissatisfied switchers and the stayers-have the potential to provide differential value above and beyond mere repeat patronage. However, we caution that though these groups of customers appear to be candidates for firm investments in acquisition and retention, further customer value assessment that explicitly identifies the profitability of these customer groups is required (e.g., Blattberg and Deighton 1996).

Second, how can service providers maximize the longterm value provided by the various customer groups? The results we present in Table 12 suggest that significant differences exist between high- and low-commitment customers within the three customer groups. In other words, firms may be positioned to extract additional value, in terms of satisfaction and loyalty behavior, from each of these customer groups by focusing on a strategy of building commitment to the relationship with the firm.

For example, although the dissatisfied switchers exhibit higher levels of satisfaction, active loyalty, and purchase involvement than the other two groups, they also exhibit lower levels of passive loyalty and ego involvement. Given our results, if firms can increase commitment among the dissatisfied switchers, they are likely to realize a significant increase in (1) ego involvement and (2) passive loyalty behaviors. Furthermore, an additional benefit may be realized in increasing high overall satisfaction to even higher levels, which has been suggested by researchers to be key to true long-term loyalty (e.g., Jones and Sasser 1995).

The results also show that stayers exhibit lower levels of active loyalty behaviors and satisfaction than dissatisfied switchers. As we illustrate in Table 12, increasing commitment among stayers is likely to increase both of these variables significantly. The last customer group, the satisfied switchers, exhibits moderate to low levels of satisfaction, loyalty behavior, and involvement. The findings indicate that increasing commitment among these customers is likely to increase (1) overall satisfaction, (2) purchase and ego involvement, and (3) active and passive loyalty behaviors. In summary, when potential areas of investment across the three customer groups are considered, building commitment appears to be a particularly efficient mechanism for increasing the incremental value of a firm's customer base.

\section{Conclusion, Limitations, and Future Research Directions}

The research presented here provides a unique and detailed investigation of what happens to customers after they switch service providers. This affords a new perspective in customer switching and loyalty research: that of the switchedto firm. The findings of this research show important differences in the customer base of a service provider and advance the knowledge of postswitching phenomena.

Although this research makes contributions to the knowledge in this area, several limitations and future research opportunities deserve mention. First, we caution that these results are confined to the retail banking industry, and further research is needed to validate and generalize these results to broader settings. However, despite this caveat, the study findings could be generalized to services that share some common characteristics with the banking industry. For example, the model proposed and tested in this study might be applicable to services that reflect the following traits: (1) switching is largely initiated by the customer, either because of dissatisfaction or other reasons (e.g., jobrelated relocation), and not by the industry (i.e., competitive poaching is relatively uncommon); (2) switching costs are relatively high and/or consumer involvement with the product/service is high; (3) customer contact and personal relationship issues take precedence over other aspects of the service in terms of selection, satisfaction, and switching; and (4) local presence of the service provider is desirable.

Legal services, accounting, insurance, and traditional brokerage services share some of these traits with banks. Because choices among these services tend to be highinvolvement decisions, the personal relationship between the contact person and the customer is often more essential relative to other aspects of the service than it is in services such as cable television. Furthermore, with regard to these services, switching to another provider often requires the time, effort, and monetary costs of evaluating information before switching. There are also time, effort, and associated costs of learning about the new service routine and rules subsequent to switching. However, our findings may not apply to services such as airline travel, hotels, or, for that matter, online banking or brokerage services, because the characteristics we discuss do not necessarily apply to these services.

Second, researchers have noted biases in self-reports of satisfaction (see Peterson and Wilson 1992), and as such the measures of satisfaction must be considered against this backdrop. Third, although the current research findings suggest that the dissatisfied switchers and the highly committed stayers have the potential to be more profitable to the firm, further research should attempt to measure the lifetime value of the customer groups explicitly. An examination of the differences in the profitability of the groups may offer concrete guidelines to firms in their quest for acquiring and retaining the right customers. Furthermore, future studies could attempt to integrate the current findings with prior switching research. For example, an approach similar to the current research but that instead uses Keveaney's (1995) customer switching framework would provide more detailed insights to switching and postswitching attitudes and behaviors. This would require a large sample.

Fourth, as mentioned previously, the research questions addressed in Study 2 are broader in scope and warrant greater attention than could be afforded in this study. The temporal aspect of changes in the service firm's customer base is a fascinating area in need of further investigation. For example, does our ten-year milestone apply to other industries, and are there other critical milestones in the tenure of a customer with a service firm? As noted by Gardial and colleagues (1993, p. 556), "Longitudinal research designs may be needed to explore how comparison standards change over time, from prepurchase to various usage points successively removed from purchase." Furthermore, other recent research calls for future studies to clarify the relative importance of the various comparison standards customers employ over time (Mittal, Kumar, and Tsiros 
1999), as well as provide a better understanding of the ongoing, dynamic, and context-specific nature of satisfaction (Fournier and Mick 1999). We recognize the difficulty in undertaking such research, but this appears to be a critical area for future studies.

A related finding addresses the notion of which switchthe most recent or the most emotionally taxing-is the salient switch. Although the limited evidence presented here suggests that the most recent switch is important, the possibility exists that the mere presence of an emotionally taxing dissatisfied switch in a customer's history may be enough to affect current satisfaction. Specifically, this memory is likely to factor into the set of knowable potential outcomes and thereby affect current expectations and levels of satisfaction (see Oliver and Winer 1987). What is needed is information on more than two switching events. A further consideration would be the inclusion of duration of stay in any future switching-sequence model.

Similarly, research on the chronically dissatisfied customer segment (customers who exhibit repeated patterns of dissatisfied switching) appears to be worthwhile. Although we found only one person who switched twice in succession because of dissatisfaction, if such customers exist in large numbers they could well be the bane of service firms. From a theoretical perspective, it is also conceivable that such customers may not conform to our switching model or, for that matter, to other models that examine updating processes on satisfaction and service quality (e.g., Boulding et al. 1993).

Furthermore, although the current study did not find any significant difference within the groups in terms of depen- dence and risk aversion, these constructs warrant further detailed examination. Recent research suggests that for relational customers, trust and commitment are likely to be important antecedents of future patronage intentions, whereas for customers who are more transaction-oriented, future patronage appears to be driven more by overall satisfaction (Garbarino and Johnson 1999). A related area to be pursued stems from the findings that stayers who exhibit lower levels of commitment are likely to be more dissatisfied than stayers who exhibit higher levels of commitment. This may suggest that today's dissatisfied stayers may well be tomorrow's dissatisfied switchers. This issue warrants more attention to improve our understanding of when and why customers defect.

Finally, our two-factor solution of the customer loyalty measures has clear analogies to Oliver's (1997) model, in which loyalty is seen as progressing through four stages: cognitive, affective, conative, and action loyalty. Our active loyalty construct describes behaviors above and beyond mere repeat patronage, such as word of mouth and expansion of service usage, and appears similar to Oliver's (1997) notion of affective loyalty. Our passive loyalty factor describes behaviors related to a customer's willingness to continue patronizing the service provider and susceptibility to competitive actions and appears to resemble Oliver's (1997) notion of conative loyalty. However, although these similarities seem logical, drawing such comparisons is exploratory and post hoc. Further research is needed to delineate the factors within the loyalty construct.

\section{REFERENCES}

Anderson, Eugene W. (1994), "Cross-Category Variation in Customer Satisfaction and Retention," Marketing Letters, 5 (1), $19-30$.

_ Claes Fornell, and Donald Lehman (1994), "Customer Satisfaction, Market Share, and Profitability: Findings from Sweden," Journal of Marketing, 58 (July), 53-66.

— and Mary W. Sullivan (1993), "The Antecedents and Consequences of Customer Satisfaction for Firms," Marketing Science, 12 (Spring), 125-43.

Anderson, James C. and James A. Narus (1990), "A Model of Distributor Firm and Manufacturer Firm Working Partnerships," Journal of Marketing, 54 (January), 42-58.

Arndt, Johan (1968), "Word of Mouth Advertising and Perceived Risk," in Perspectives in Consumer Behavior, Harold H. Kassarjian and Thomas S. Robertson, eds. Glenview, IL: Scott, Foresman, 330-36.

Assael, Henry (1987), Consumer Behavior and Marketing Action, 3d ed. Boston: PWS-Kent.

Baumgartner, Hans and Jan-Benedict E.M. Steenkamp (1996), "Exploratory Consumer Buying Behavior: Conceptualization and Measurement," International Journal of Research in Marketing, 13 (2), 121-37.

Bearden, William O. and Jesse E. Teel (1983), "Selected Determinants of Consumer Satisfaction and Complaint Reports," Journal of Marketing Research, 20 (February), 21-28.

Beatty, Sharon, Lynn R. Kahle, and Pamela Homer (1988), "The Involvement-Commitment Model: Theory and Implications," Journal of Business Research, 16 (2), 149-67.

— and Scott M. Smith (1987), "External Search Effort: An Investigation Across Several Product Categories," Journal of Consumer Research, 14 (June), 83-95.
Bendapudi, Neeli and Leonard L. Berry (1997), "Customers' Motivations for Maintaining Relationships with Service Providers," Journal of Retailing, 73 (Spring), 15-37.

Berlyne, D.E. (1960), Conflict, Arousal and Curiosity. New York: McGraw-Hill.

Berry, Leonard L. (1983), "Relationship Marketing," in Emerging Perspectives on Services Marketing, Leonard L. Berry, Lynn Shostack, and Gregory Upah, eds. Chicago: American Marketing Association, 25-28.

Bitner, Mary Jo, Bernard M. Booms, and Lois A. Mohr (1994), "Critical Service Encounters: The Employee's Viewpoint," Journal of Marketing, 58 (October), 95-106.

Blattberg, Robert C. and John Deighton (1996), "Manage Marketing by the Customer Equity Test," Harvard Business Review, 74 (July/August), 136-44.

Bloch, Peter H. (1982), "Involvement Beyond the Purchase Process: Conceptual Issues and Empirical Investigation," in Advances in Consumer Research, Vol. 9, Andrew Mitchell, ed. Ann Arbor, MI: Association for Consumer Research, 413-17.

- and Marsha L. Richins (1983), "A Theoretical Model for the Study of Product Importance Perceptions," Journal of Marketing, 47 (Summer), 69-81.

Bloemer, Jose M.M. and Hans D.P. Kasper (1995), "The Complex Relationship Between Consumer Satisfaction and Brand Loyalty," Journal of Economic Psychology, 16 (July), 311-29.

Boulding, William, Ajay Kalra, Richard Staelin, and Valerie Zeithaml (1993), "A Dynamic Process Model of Service Quality: From Expectations to Behavioral Intentions," Journal of Marketing Research, 30 (February), 7-27.

Brehm, Jack W. (1966), A Theory of Psychological Reactance. New York: Academic Press. 
Burke, Raymond R. and Thomas K. Srull (1988), "Competitive Interference and Consumer Memory for Advertising," Journal of Consumer Research, 15 (June), 55-68.

Cadotte, Ernest R., Robert B. Woodruff, and Roger L. Jenkins (1987), "Expectations and Norms in Models of Consumer Satisfaction," Journal of Marketing Research, 24 (August), 305-14.

Churchill, Gilbert A., Jr., and Carol Surprenant (1982), "An Investigation into the Determinants of Customer Satisfaction," Journal of Marketing Research, 19 (November), 491-504.

Cohen, Joel B. (1983), "Involvement and You: 1000 Great Ideas," in Advances in Consumer Research, Vol. 10, Richard Bagozzi and A. Tybout, eds. Ann Arbor, MI: Association for Consumer Research, 325-28.

Crano, William D. (1977), "Primacy and Recency in Retention of Information and Opinion Change," Journal of Social Psychology, 101 (February), 87-96.

Crosby, Lawrence A., Kenneth R. Evans, and Deborah Cowles (1990), "Relationship Quality in Services Selling: An Interpersonal Influence Perspective," Journal of Marketing, 54 (July), $68-81$.

and Nancy Stephens (1987), "Effects of Relationship Marketing on Satisfaction, Retention, and Prices in the Life Insurance Industry," Journal of Marketing Research, 24 (November), 404-11.

Crowder, R.D. (1976), Principles of Learning and Memory. Hillsdale, NJ: Lawrence Erlbaum Associates.

Czepiel, John A. (1990), "Service Encounters and Service Relationships: Implications for Research," Journal of Business Research, 20 (1), 13-21.

Day, George S. (1969), "A Two-Dimensional Concept of Brand Loyalty," Journal of Advertising, 9 (3), 29-35.

Dick, Alan S. and Kunal Basu (1994), "Customer Loyalty: Toward an Integrated Conceptual Framework," Journal of the Academy of Marketing Science, 22 (2), 99-113.

Dowling, Graham R. and Mark Uncles (1997), "Do Customer Loyalty Programs Really Work?" Sloan Management Review, 38 (Summer), 71-82.

Folkes, Valerie S. (1988), "The Availability Heuristic and Perceived Risk," Journal of Consumer Research, 15 (June), 13-23. - (1994), "How Consumers Predict Service Quality: What Do They Expect?" in Service Quality: New Directions in Theory and Practice, Roland T. Rust and Richard L. Oliver, eds. Thousand Oaks, CA: Sage Publications, 108-22.

Fornell, Claes (1992), "A National Customer Satisfaction Barometer: The Swedish Experience," Journal of Marketing, 56 (January), 6-21.

, Michael D. Johnson, Eugene W. Anderson, Jaesung Cha, and Barbara Everitt Bryant (1996), "The American Customer Satisfaction Index: Nature, Purpose, and Findings," Journal of Marketing, 60 (October), 7-18.

Fournier, Susan and David Glen Mick (1999), "Rediscovering Satisfaction," Journal of Marketing, 63 (October), 5-23.

Ganesan, Shankar (1994), "Determinants of Long-Term Orientation in Buyer-Seller Relationships," Journal of Marketing, 58 (April), 1-19.

Garbarino, Ellen and Mark S. Johnson (1999), “The Different Roles of Satisfaction, Trust and Commitment in Customer Relationships," Journal of Marketing, 63 (April), 70-87.

Gardial, Sarah Fisher, D. Scott Clemons, Robert B. Woodruff, David W. Schumann, and Mary Jane Burns (1993), "Comparing Consumers' Recall of Prepurchase and Postpurchase Product Evaluation Experiences," Journal of Consumer Research, 20 (March), 548-60.

Goff, Brent G., James S. Boles, Danny N. Bellenger, and Carrie Stojack (1997), "The Influence of Salesperson Selling Behaviors on Customer Satisfaction with Products," Journal of Retailing, 73 (Summer), 171-84.
Greene, Robert L. (1986), "Sources of Recency Effects in Free Recall," Psychological Bulletin, 99 (2), 221-28.

Guiltinan, Joseph P. (1989), "A Classification of Switching Costs with Implications for Relationship Marketing," in 1989 AMA Winter Educators' Conference: Marketing Theory and Practice, T.L. Childers, R.P. Bagozzi, and J.P. Peter, eds. Chicago: American Marketing Association, 216-20.

Helson, Harry (1964), Adaptation-Level Theory. New York: Harper and Row.

Houston, Michael J. and L.M. Rothschild (1978), "A Paradigm for Research on Consumer Involvement," Working Paper No. 1177-46, University of Wisconsin, Madison.

Iacobucci, Dawn and Amy Ostrom (1996), "Commercial and Interpersonal Relationships: Using the Structure of Interpersonal Relationships to Understand Individual-to-Individual, Individual-to-Firm, and Firm-to-Firm Relationships in Commerce," International Journal of Research in Marketing, 13 (February), 53-72.

Jacoby, Jacob and Robert W. Chestnut (1978), Brand Loyalty: Measurement and Management. New York: John Wiley \& Sons.

and David B. Kyner (1973), "Brand Loyalty vs. Repeat Purchasing Behavior," Journal of Marketing Research, 10 (February), 1-9.

Jones, Thomas O. and Earl W. Sasser Jr. (1995), "Why Satisfied Customers Defect," Harvard Business Review, 73 (November/December), 88-99.

Keaveney, Susan (1995), "Customer Switching Behavior in Service Industries: An Exploratory Study," Journal of Marketing, 59 (April), 71-82.

Kelley, Scott W., K. Douglas Hoffman, and Mark A. Davis (1993), "A Typology of Retail Failures and Recoveries," Journal of Retailing, 69 (Winter), 429-52.

LaBarbera, Priscilla and David Mazursky (1983), “A Longitudinal Assessment of Consumer Satisfaction/Dissatisfaction: The Dynamic Aspect of the Cognitive Process," Journal of Marketing Research, 20 (November), 393-404.

LaTour, Stephen A. and Nancy C. Peat (1979), "Conceptual and Methodological Issues in Consumer Satisfaction Research," in Advances in Consumer Research, Vol. 6, William F. Wilkie, ed. Ann Arbor, MI: Association for Consumer Research, 431-37. and (1980), "The Role of Situationally-Produced Expectations, Others' Experiences, and Prior Experience in Determining Consumer Satisfaction," in Advances in Consumer Research, Vol. 7, Jerry C. Olson, ed. Ann Arbor, MI: Association for Consumer Research, 588-92.

Laurent, Gilles and Jean-Noel Kapferer (1985), "Measuring Consumer Involvement Profiles," Journal of Marketing Research, 22 (February), 41-53.

Mazursky, David, Priscilla LaBarbera, and Al Aiello (1987), "When Consumers Switch Brands," Psychology and Marketing, 4 (Spring), 17-30.

Mittal, Banwari (1989), "Measuring Purchase Decision Involvement," Psychology and Marketing, 6 (2), 147-62.

— and Myung-soo Lee (1989), "A Causal Model of Consumer Involvement," Journal of Economic Psychology, 10 (November), 363-89.

Mittal, Vikas, Pankaj Kumar, and Michael Tsiros (1999), "Attribute-Level Performance, Satisfaction and Behavioral Intentions over Time: A Consumption-System Approach," Journal of Marketing, 63 (April), 88-101.

Morgan, Robert M. and Shelby D. Hunt (1994), "The Commitment-Trust Theory of Relationship Marketing," Journal of Marketing, 58 (July), 20-38.

Nunnally, Jum C. (1978), Psychometric Theory. New York: McGraw-Hill.

O'Brien, Louise and Charles Jones (1995), "Do Rewards Really Create Loyalty?" Harvard Business Review, 73 (May/June), 75-83. 
Oliva, Terence, Richard L. Oliver, and Ian MacMillan (1992), “A Catastrophe Model For Developing Service Satisfaction Strategies," Journal of Marketing, 56 (July), 83-95.

Oliver, Richard L. (1980), "A Cognitive Model of the Antecedents and Consequences of Satisfaction Decisions," Journal of Marketing Research, 17 (November), 460-69.

(1992), "An Investigation of the Attribute Basis of Emotion and Related Affects in Consumption: Suggestions for a Stage-Specific Satisfaction Framework," in Advances in Consumer Research, Vol. 19, John Sherry and Brian Sternthal, eds. Ann Arbor, MI: Association for Consumer Research, 237-44.

(1993), "Cognitive, Affective, and Attribute Bases of the Satisfaction Response," Journal of Consumer Research, 20 (December), 418-30.

(1997), Satisfaction: A Behavioral Perspective on the Consumer. Boston: Richard D. Irwin/McGraw-Hill.

and John E. Swan (1989), "Consumer Perceptions of Interpersonal Equity and Satisfaction in Transactions: A Field Survey Approach," Journal of Marketing, 53 (April), 21-35.

— and Russell S. Winer (1987), "A Framework for the Formation and Structure of Consumer Expectations: Review and Propositions," Journal of Economic Psychology, 8 (December), 469-99.

Ostrom, Amy and Dawn Iacobucci (1995), "Consumer Tradeoffs and the Evaluation of Services," Journal of Marketing, 59 (January), 17-28.

Parasuraman, A., Valarie A. Zeithaml, and Leonard L. Berry (1985), "A Conceptual Model of Service Quality and Its Implications for Future Research,” Journal of Marketing, 49 (Fall), $41-50$.

- - (1988), "SERVQUAL: A MultipleItem Scale for Measuring Consumer Perceptions of Service Quality," Journal of Retailing, 64 (Spring), 12-37.

-, , and (1994), "Reassessment of Expectations as a Comparison Standard in Measuring Service Quality: Implications for Further Research," Journal of Marketing, 58 (January), 111-24.

Pearlin, Leonard I. and Carmi Schooler (1978), "The Structure of Coping," Journal of Health and Social Behavior, 19 (March), 2-21.

Peterson, Robert A. and William Wilson (1992), "Measuring Customer Satisfaction: Fact and Artifact," Journal of Academy of Marketing Science, 20 (1), 61-71.

Pieters, Rik G.M. and Tammo H.A. Bijmolt (1997), "Consumer Memory for Television Advertising: A Field Study of Duration, Serial Position, and Competition Effects," Journal of Consumer Research, 23 (March), 362-72.

Ping, Robert A. (1993), "The Effects of Satisfaction and Structural Constraints on Retailer Exiting, Voice, Loyalty, Opportunism and Neglect," Journal of Retailing, 69 (Fall), 320-52.

Raju, P.S. (1980), "Optimum Stimulation Level: Its Relationship to Personality, Demographics and Exploratory Behavior," Journal of Consumer Research, 7 (December), 272-82.

Reichheld, Frederick F. (1993), "Loyalty-Based Management," Harvard Business Review, 71 (March/April), 64-73. and David W. Kenny (1990), “The Hidden Advantages of Customer Retention," Journal of Retail Banking, 4 (Winter), 19-23.

and Thomas Teal (1996), The Loyalty Effect. Boston: Harvard Business School Press.

Richins, Marsha L. and Peter H. Bloch, (1986), "After the New Wears Off: The Temporal Context of Product Involvement," Journal of Consumer Research, 13 (September), 280-85.

Rust, Ronald T. and Anthony J. Zahorik (1993), "Customer Satisfaction, Customer Retention, and Market Share," Journal of Retailing, 69 (Summer), 193-215.

Salma, Mark E. and Armen Tashchain (1985), "Selected Socioeconomic and Demographic Characteristics Associated with Purchasing Involvement," Journal of Marketing, 49 (Winter), 72-82.

Sherif, Carolyn W., Musafer Sherif, and Roger E. Nebergall (1965), Attitude and Attitude Change. Philadelphia: Saunders.

Sherif, Musafer and H. Cantril (1947), The Psychology of EgoInvolvement. New York: John Wiley \& Sons.

Swan, John E. and Richard L. Oliver (1989), "Post-purchase Communications by Consumers," Journal of Retailing, 65 (Winter), 516-33.

Thibaut, John W. and Harold H. Kelley (1959), The Social Psychology of Groups. New York: John Wiley \& Sons.

Tse, David K. and Peter C. Wilton (1988), "Models of Consumer Satisfaction Formation: An Extension," Journal of Marketing Research, 25 (May), 204-12.

Tversky, Amos and Daniel Kahneman (1974), "Judgement Under Uncertainty: Heuristics and Biases," Science, 185 (September), 1124-31.

Westbrook, Robert A. (1981), "Sources of Consumer Satisfaction with Retail Outlets," Journal of Retailing, 57 (Fall), 68-85.

___ (1987), "Product/Consumption-Based Affective Responses and Post-purchase Processes," Journal of Marketing Research, 24 (August), 258-70.

— and Richard L. Oliver (1981), "Developing Better Measures of Consumer Satisfaction: Some Preliminary Results," in Advances in Consumer Research, Vol. 8, Kent B. Monroe, ed. Ann Arbor, MI: Association for Consumer Research, 94-99.

Woodruff, Robert B., Ernest R. Cadotte, and Roger L. Jenkins (1983), "Modeling Consumer Satisfaction Processes Using Experience-Based Norms," Journal of Marketing Research, 20 (August), 296-304.

Zaichkowsky, Judith Lynne (1985), "Measuring the Involvement Construct," Journal of Consumer Research, 12 (December), 341-52.

Zeithaml, Valarie A., Leonard L. Berry, and A. Parasuraman (1993), "The Nature and Determinants of Customer Expectations of Service," Journal of the Academy of Marketing Science, 21 (Winter), 1-12.

- (1996), "The Behavioral Consequences of Service Quality,” Journal of Marketing, 60 (April), 31-46. 